\title{
LA GRAN CRISIS FINANCIERA DE 2007-2009*
}

\author{
Vittorio Corbo, Jorge Desormeaux M. \\ y Klaus Schmidt-Hebbel
}

\begin{abstract}
Resumen: ¿En qué medida fue la Gran Crisis Financiera del 2007-2009 semejante a crisis anteriores, y cuáles fueron sus causas? El propósito de este trabajo es explorar estas preguntas, presentando el patrón tradicional seguido por crisis financieras en el pasado, una cronología de la crisis reciente, y luego un análisis en profundidad de las causas de ésta. El análisis de las causas de la crisis está separado en tres partes: aquellas que crean la oportunidad para que se generen distorsiones en el sistema financiero, aquellas que explican la voluntad por parte del sistema financiero para aprovecharlas,
\end{abstract}

VitTorio Corbo. Ingeniero Comercial, Universidad de Chile y Ph. D. en Economía, Massachusetts Institute of Technology (MIT). Investigador Asociado Senior, CEP, Santiago-Chile (vcorbo@cepchile.cl).

Jorge Desormeaux. Ingeniero Comercial y Magister en Economía Financiera, Pontificia Universidad Católica. Candidato de MBA (2013), MIT Sloan, Boston-EE.UU. (jorge.desormeaux@sloan.mit.edu).

Klaus Schmidt-Hebbel. Ph. D. en Economía, Massachusetts Institute of Technology (MIT). Profesor titular de la Pontificia Universidad Católica de Chile, Santiago-Chile (kschmidt-hebbel@uc.cl).

* Agradecemos los valiosos comentarios de tres referees anónimos. 
y aquellas responsables por el descuido de la institucionalidad regulatoria y supervisora dedicada a prevenir esta clase de eventos. En último término, la crisis fue producto de una serie de factores, algunos de los cuales son tradicionales y otros nuevos. Distinguir con claridad entre causas de la crisis y los síntomas de ésta es esencial para el diseño de políticas de regulación adecuadas.

Palabras clave: crisis financiera internacional, fallas de mercado, fallas de regulación, sistema financiero, recesión mundial.

Clasificación JEL: E32, F34, G01, G15, G32.

Recibido: julio 2011; aceptado: septiembre 2011.

THE GREAT FINANCIAL CRISIS OF 2007-2009

Vittorio Corbo, Jorge Desormeaux M. and

Klaus Schmidt-Hebbel

Abstract: To what extent was the Great Financial Crisis of 2007-2009 similar to previous crises, and what were the main causes behind it? The purpose of this paper is to explore these questions, presenting the traditional pattern followed by financial crises in the past, a chronology of the recent crisis, and an in-depth analysis of its causes. We distinguish between three different classes of causes in our analysis: those which created the opportunity for severe distortions to arise in the financial system, those which explain the desire of the financial system to take advantage of them, and those responsible for the neglect shown by our regulatory and supervisory frameworks to rein them in and avoid a catastrophic event. The crisis was caused by a complex series of factors, some of which are traditional, and others are new to our experience. Distinguishing clearly between main causes and mere symptoms of the crisis is essential for the design of adequate regulatory policy.

Keywords: international financial crisis, market failures, regulation failures, financial system, world recession.

JEL Classification: E32, F34, G01, G15, G32.

Received: July 2011; accepted: September 2011 . 


\section{Introducción}

De esde el punto de vista de un observador chileno, la Gran Crisis Financiera (GCF) de 2007-2009 puede asemejarse al terremoto que golpeó a Chile el 27 de febrero de 2010, una fuerza de la naturaleza, catastrófica e imprevisible, que ocurre no más de una vez por generación. La comparación es apta en varios sentidos:

- $\quad$ En primer lugar, tal como los terremotos catastróficos — ha habido 13 en el mundo con una magnitud de 8 o superior en la última década_-, las crisis financieras son más comunes de lo que las personas suelen pensar. Así, el mundo ha vivido ocho crisis financieras importantes (es decir, con repercusiones significativas en los mercados internacionales) en las últimas dos décadas.

- $\quad$ En segundo lugar, si bien no es posible predecir ni crisis financieras ni terremotos, es posible tomar precauciones y prepararse para enfrentar mejor dichos eventos. Es instructivo el caso de Chile, que sufrió un terremoto 500 veces más intenso que el de Haití en 2010, pero tuvo 287 veces menos víctimas fatales (800 contra 230.000), tal como las instituciones financieras de países con una situación macroeconómica equilibrada y con mejor regulación y supervisión financiera sufrieron menos daño durante la GCF.

- $\quad$ En tercer lugar, tanto las crisis financieras como los terremotos presentan patrones que debieran ser de interés no sólo para el historiador, científico o economista, sino también para aquellos que trabajan en sectores afectados (como son la intermediación financiera y la construcción, respectivamente) y en las agencias públicas que los regulan y supervisan ${ }^{1}$.

Por supuesto, la analogía entre crisis financieras y terremotos no es perfecta. Hay diferencias importantes, como el hecho que las fallas que dan origen a los terremotos son fenómenos naturales que ocurren en una escala de tiempo geológica. Son moderadamente conocidas, y si bien no es posible predecir cuándo va a ocurrir un terremoto, el conoci-

${ }^{1}$ A diferencia del frecuente empleo del término supervisión, que en idioma inglés engloba a la regulación y a la supervisión propiamente tal, distinguiremos en este artículo entre regulación y supervisión. 
miento respecto del dónde y cuán peligroso está más desarrollado. Sin embargo, en el mundo financiero, las fallas o debilidades que crean el peligro de una gran crisis financiera dependen del actuar humano y se mueven en una escala de tiempo distinta. Su geografía es desconocida e inestable, dificultando la estimación de la probabilidad, la localidad y la intensidad de su ocurrencia.

Sin embargo, a nuestro juicio, la diferencia más importante es una de conocimiento y percepción. El público general entiende, en mayor o menor grado, por qué ocurren los terremotos y cómo comportarse cuando ocurre uno. Pero ello no es tan cierto en las crisis financieras - aún no existe una teoría unificada de sus causas, no se sabe bien cómo prevenirlas ni tampoco cómo enfrentarlas cuando se producen.

El estudio sistemático de las crisis financieras por los economistas es sorprendentemente reciente - lo que contrasta con ocho siglos de crisis financieras, según Reinhart y Rogoff (2009). Hoy contamos con tres libros muy influyentes que caracterizan y describen causas, desarrollos y consecuencias de crisis financieras. La primera edición de la obra seminal, Manias, Panics and Crashes, fue escrita por Kindleberger en 1978. Luego está el volumen de Minsky (1986) y, recientemente, el muy bien documentado volumen ya citado de Reinhart y Rogoff, que presenta un vasto y sistemático material estadístico sobre la historia de las crisis financieras en el mundo.

Aún más recientes son los modelos analíticos o teóricos de crisis financieras. Ellos tienden a centrarse en una falla o imperfección específica, ya sea de mercado o de política, que, en condiciones de un shock adverso, llevan a la quiebra de un sistema financiero o de un país y al colapso de precios de activos y del crédito interno o externo. Aquí el paper seminal es el de Diamond y Dybvig (1983) sobre crisis bancarias, que luego ha sido generalizado para analizar crisis financieras en economías abiertas, incluyendo crisis cambiarias y de repudio de deuda externa. Quizás no sorprendentemente, un número notable de modelos teóricos de crisis financieras, desarrollados antes de la GCF, son de economistas chilenos y latinoamericanos, como Goldfajn y Valdés (1997), Chang y Velasco (2001), Calvo (2003) y Caballero y Krishnamurthy (2001, 2008). Después de la GCF se observa una explosión de trabajos teóricos, pero es aún muy temprano para hacer una evaluación de éstos. Aunque todos estos esfuerzos explican ciertos aspectos de las crisis, la economía está aún lejos de disponer de un cuerpo unificado — una gran teoría - para explicar las crisis financieras. 
En contraposición a este gran reto que enfrenta la disciplina económica, el propósito de este trabajo es modesto. Nuestra meta es caracterizar esta crisis financiera y sus causas subyacentes, e indicar en qué medida se apega al patrón establecido por crisis anteriores y qué desarrollos son nuevos. Idealmente, un lector atento terminará la crónica con una idea bien formada de por qué ocurren crisis financieras y cómo éstas se desenvuelven, y contará con alguna preparación para enfrentar el próximo sismo financiero.

En la sección II hacemos una descripción de la anatomía de una crisis financiera: qué características tiene, por qué razones ocurre, cuál es la dinámica que sigue una vez que se gatilla y cómo las autoridades suelen responder a su presencia. Los conceptos que se introducen en esta sección son importantes para el análisis que se hace en secciones posteriores y proveen un trasfondo para aquellos lectores que no han estudiado el tema.

La sección III es una descripción narrativa de la Gran Crisis Financiera, en que comenzamos caracterizando el ambiente previo y luego las tres fases que ésta siguió. Al igual que la sección II, esta sección debiera ser especialmente útil para aquellos que no han seguido la cronología de la crisis.

Las secciones IV, V y VI son un análisis en detalle de los tres ingredientes necesarios para que ocurra una crisis financiera: oportunidad de que se creen distorsiones, la voluntad para aprovecharlas y el descuido por parte de las autoridades financieras que permite que todo ocurra. Algunos de los factores que constituyen estos ingredientes son tradicionales en crisis financieras, mientras que otros son nuevos desarrollos que vienen de la mano con los avances de nuestro sistema financiero.

Finalmente, la sección VII hace una síntesis del análisis y presenta nuestras conclusiones sobre las causas de la Gran Crisis Financiera.

\section{La anatomía de una crisis financiera}

Las crisis del sector financiero son fundamentalmente distintas a las crisis que afectan a un sector real. Enumeramos estas diferencias en el siguiente decálogo de características idiosincráticas a las crisis financieras: 
(1) Las crisis financieras tienden a ser precedidas por períodos de bonanza, caracterizados por una elevada expansión del crédito y fuertes aumentos en los precios de activos - activos financieros (como acciones o bonos) y activos reales (como propiedades inmobiliarias). Después de declarada la crisis, tiende a ser evidente que la expansión del crédito era insostenible, varios sectores de la economía están sobrendeudados y no serán capaces de pagar sus obligaciones, y que los precios de activos tenían importantes componentes de burbujas, habiéndose alejado de sus valores fundamentales.

(2) Las causas profundas de las crisis son combinaciones de algunas fallas de mercado (fallas en el funcionamiento de los mercados privados) y fallas de política (políticas fiscales y monetarias insostenibles, y fallas en la regulación y supervisión pública de los mercados financieros privados). Las fallas específicas — en todo su detalle- son distintas en cada crisis; típicamente se hacen evidentes recién con posterioridad a las crisis.

(3) Las crisis financieras son sistémicas, en el sentido que afectan a una parte significativa de las transacciones financieras y los intermediarios financieros de un país.

(4) Los eventos puntuales o gatillos de crisis financieras - como las suspensiones de las operaciones financieras de determinados activos o agentes financieros o sus intervenciones por los gobiernos- no constituyen típicamente las causas profundas de las crisis, sino más bien son su manifestación.

(5) Las crisis financieras no sólo afectan a las instituciones financieras débiles sino que contagian a subsectores financieros y empresas financieras que previamente se encontraban en buen estado.

(6) Las crisis financieras en países muy conectados con los mercados financieros importantes (los países del este asiático en 1997-98, Rusia en 1998, EE.UU. en 2007-08) pueden transmitirse velozmente a otros países y regiones. En cambio las crisis en países poco importantes para el sistema financiero internacional y con poca conexión con otros mercados financieros no tienen repercusiones globales (Finlandia 1991). Dada la importante interconexión entre los mercados financieros de los últimos 15 años, las crisis tienen cada vez más repercusiones a nivel internacional. De hecho, Grecia tiene algo más del $2 \%$ del PIB de la zona euro y sus crisis han estado golpeando a toda la zona euro.

(7) Los efectos financieros agregados de las crisis incluyen una interrupción significativa del crédito, cambios significativos en las con- 
diciones bajo las cuales se otorga el crédito, cambios bruscos en precios y rendimientos de activos financieros, reducciones significativas en las transacciones de muchos activos financieros, y quiebras o intervenciones de intermediarios financieros sistémicamente importantes y secundarios.

(8) Los efectos reales agregados de las crisis - transmitidos a través de restricciones del crédito y de sus condiciones, y de cambios en precios relativos - son caídas en ventas agregadas y, luego, en la producción y el empleo nacional. Las dificultades financieras y las quiebras de empresas reales gatilladas por la crisis llevan a la suspensión del pago de sus deudas con el sector financiero, profundizando las crisis financieras.

(9) El riesgo de la implosión financiera y real de las economías en crisis financiera lleva a los gobiernos a adoptar medidas de intervención y/o rescate de las instituciones financieras afectadas y a implementar políticas macroeconómicas expansivas.

(10) La reconstrucción de los sistemas financieros en crisis y las recuperaciones reales de las economías tienden a ser lentas - mucho más lentas que la recuperación de recesiones que no han estado acompañadas de crisis financieras.

En lo que sigue nos referiremos a algunas de las obras más importantes que describen el desarrollo de una crisis financiera y que discuten algunas de las características anteriores en mayor detalle.

El tercer capítulo de Kindleberger (2005) discute por qué ocurren las "manías especulativas" que frecuentemente preceden a las crisis financieras. Resalta dos características útiles para nuestro análisis. Primero, los precios de los activos están determinados por las expectativas sobre sus rendimientos futuros. Por lo tanto, dependen de factores evanescentes, como pueden ser el grado de confianza económica, las creencias sobre la capacidad y los intereses de un candidato presidencial o las expectativas del potencial comercial de una nueva tecnología. Por ello, las condiciones de confianza, optimismo y finalmente de euforia marcan el desarrollo del período de bonanza que típicamente precede una crisis. Segundo, las burbujas de precios son coherentes con un comportamiento racional de los inversionistas. Un ejemplo de ello es la teoría del "tonto más grande"2, que explica que un agente puede estar perfectamente

2 "The greater fool theory". 
consciente de que el precio de un activo está sobrevalorado (en el sentido que su precio excede al valor presente de sus rendimientos futuros), pero decide comprar dicho activo en espera de que el precio siga aumentando para luego venderlo - antes del desplome - a un "tonto más grande".

La hipótesis de inestabilidad financiera de Minsky (1986) dibuja una relación entre la precariedad de los precios de activos y las decisiones de inversión con las crisis financieras. En el modelo de Minksy, los eventos que conducen a una crisis financiera comienzan con un cambio que beneficia a uno o más sectores de la economía — por ejemplo, un fuerte aumento en la demanda por commodities $^{3}$, causada por la expansión de China, que lleva a un aumento sostenido en los precios mundiales de éstos. Así, las personas y empresas se endeudan para comprar acciones de empresas productoras de commodities, para comprar tierra agrícola y minera, y para realizar inversiones destinadas a aumentar la capacidad productiva de los commodities en alta demanda. Este aumento en el endeudamiento y la inversión genera crecimiento económico y un mayor nivel de optimismo sobre el futuro, creando un círculo virtuoso. La bonanza no se limita a los commodities iniciales: aquellas empresas que prestan servicios o contribuyen a la actividad también se benefician. Se abren nuevas oportunidades para enriquecerse y las instituciones financieras extienden crédito a personas y empresas que buscan aprovecharlas.

La raíz de las crisis financieras está en este proceso de endeudamiento, en el ciclo del crédito. Cuando se da un clima de optimismo y expansión económica, los estándares de evaluación de riesgo se flexibilizan y la disponibilidad de crédito aumenta fuertemente. Sin embargo, no todos los proyectos que se financian son prudentes o serán exitosos. No todas las empresas que se endeudan serán capaces de pagar sus obligaciones. Posiblemente muchos de los activos financieros que se compren con deuda estarán sobrevaluados. En un ambiente de dinero fácil, optimismo y confianza, también se abre la oportunidad para el fraude: aparecen los Ponzi y los Madoff, cuyos esquemas piramidales crecen exponencialmente durante la bonanza.

Pero la euforia no es sostenible. Sucederá un evento adverso no anticipado — una revolución en los países árabes, un terremoto en

${ }^{3}$ Los commodities son materias primas que sirven de insumos para la producción industrial o la construcción (como el cobre) o bienes finales (como el trigo), de origen minero o agrícola, comerciados a granel y típicamente son bienes homogéneos o de diferenciación baja. 
Japón, una quiebra de un banco o de un país sistémicamente importante- que gatillará una masiva corrección de las expectativas optimistas. Primero cesa el aumento en los precios de los activos. Aquellos modelos de negocios que sólo pueden sobrevivir en la medida que los precios sigan y sigan en aumento son incapaces de pagar sus obligaciones: quedan desenmascarados los Ponzi y los Madoff. El mercado se da cuenta que algunas empresas están en apuros — pero no es inmediatamente evidente quiénes son. El mercado se da cuenta de que los precios de muchos activos están demasiado altos — pero desconoce cuál es el precio correcto. Dada la incertidumbre, desaparecen los compradores, y como consecuencia se derrumban los precios en los mercados afectados. El sistema financiero congela el crédito y aquellas empresas y personas más endeudadas y afectadas por la crisis en desarrollo cesan el pago de su deuda. Y tal como la expansión de crédito apuntaló un fuerte optimismo económico y un gran crecimiento, la súbita contracción del crédito que coincide con la quiebra de proyectos y empresas que se endeudaron de manera excesiva lleva a una recesión económica. Con ello se cierra el patrón de euforia, exceso y pánico que caracteriza el ciclo completo que culmina en la crisis financiera.

En contraste con los sectores reales, la naturaleza del sistema financiero lo hace frágil y susceptible al contagio durante episodios de pánico. El negocio principal de un banco es pedir prestado a corto plazo, en la forma de depósitos, y luego prestar estos fondos a más largo plazo, en la forma de créditos. Este descalce de plazos implica, en ausencia de certidumbre sobre la calidad de los créditos, un riesgo de descalce, que es moderado en tiempos normales pero que se hace agudo en tiempos de crisis, cuando la calidad de los créditos se deteriora. Como el público no es capaz de observar en qué se está usando su dinero ni cuán competente y disciplinado es un banco, retira sus depósitos de todos los bancos y se vuelca hacia activos alternativos de alta liquidez (la liquidez de un activo es el grado en que éste se puede comprar o vender sin afectar el precio; activos de alta liquidez son fáciles de comprar y vender). En ausencia de intervención del gobierno, puede darse una corrida bancaria en que potencialmente todo el sistema bancario quiebre. No es necesario que siquiera un banco esté realmente en riesgo de no poder pagar a sus clientes: sólo la sospecha o el miedo de tal escenario es suficiente. Además, considerando la integración financiera internacional reflejada en el elevado monto de créditos privados internacionales y 
la existencia de bancos globales, el contagio puede saltar fácilmente a través de fronteras nacionales.

A la luz de las características anteriores de los sistemas financieros y de los enormes costos reales que se derivan de las crisis financieras, se justifica el tratamiento especial que históricamente han dado los gobiernos a instituciones financieras durante y después de una crisis. Previo a una crisis, el gobierno tiene la responsabilidad de adoptar las mejores prácticas internacionales en materia de regulación y supervisión financiera, a fin de evitar la toma excesiva de riesgo por los intermediarios financieros, aumentar la información que proveen dichos intermediarios a los mercados $\mathrm{y}$, en general, alinear los intereses de los dueños y gestores de dichos intermediarios con los del público general. Además, para evitar una corrida contra instituciones que hacen intermediación de plazos, los gobiernos pueden implementar seguros de depósitos y facultades que permitan al Banco Central ofrecer apoyo a instituciones financieras solventes. Lamentablemente es difícil lograr una buena implementación de los principios anteriores, como discutiremos posteriormente.

Una vez declarada la crisis financiera, los gobiernos tienden a intervenir mucho más allá de sus obligaciones legales (reflejadas fundamentalmente en los seguros de depósitos bancarios), interviniendo a los intermediarios financieros en falencia y rescatando a aquellos que son sistémicamente importantes. Estas intervenciones y rescates combinan los reemplazos de ejecutivos y controladores privados por interventores públicos, las concesiones de líneas de créditos de emergencia, los aportes de capital, las reestructuraciones de deuda interna y externa, y las consolidaciones de intermediarios financieros. Este masivo papel que juegan los gobiernos en los sectores financieros en crisis - casi impensable en otros sectores reales- es justificado por los elevados costos reales que las economías pagarían en su ausencia. No obstante, el conocimiento ex ante de esta función de rescate ex post también lleva a la excesiva toma de riesgo por los intermediarios financieros durante las bonanzas, que nuevamente debe ser limitada por una regulación y supervisión inteligentemente diseñadas e implementadas.

No todas las crisis financieras son iguales - de hecho, son muy distintas en su génesis, su desarrollo y sus consecuencias. El daño que causan a la economía puede ser leve, como fue en EE.UU. con la quiebra de miles de asociaciones de ahorros y préstamos (savings and 
loans, también conocidas como thrifts) entre 1986 y 1995. El costo neto de esta crisis para los ciudadanos americanos fue aproximadamente US\$ 124 mil millones (Curry y Shibut, 2002), lo que es modesto para los estándares de una crisis financiera. Pero el daño que éstas causan también puede ser terrible, como fue el caso para muchos países del mundo durante la Gran Depresión de los años 1930 y de muchos países latinoamericanos durante la crisis de la deuda en los años 1980. Chile fue el país más afectado del mundo por ambas crisis financieras y recesiones internacionales: el PIB real chileno se contrajo 45,6\% entre 1929 y 1932 , y se contrajo $16,1 \%$ entre 1981 y 1983 .

Reinhart y Rogoff (2009) señalan que el grado de daño económico que causan las crisis financieras depende mayormente de la intensidad y duración y de cuán fuerte y duradera es la contracción de crédito, que a su vez depende del grado de destrucción que el sistema financiero sufre durante la crisis. El nivel de daño depende fundamentalmente del nivel de endeudamiento involucrado: en aquellas crisis especulativas en que la compra de activos no se financió con deuda, como lo fue la crisis puntocom, el colapso en los precios sólo causa una pérdida de riqueza a los inversionistas y no hay repercusiones mayores.

Los autores anteriores indican que una crisis bancaria está asociada a una caída en el PIB de 9\%, en promedio, que tarda más de dos años en recuperarse. El efecto en el desempleo es aún mayor: la tasa de desempleo aumenta 7 puntos porcentuales, en promedio, durante los cuatro años siguientes. En un estudio más reciente de la experiencia mundial de crisis bancarias, el FMI concluye que, al séptimo año después de una crisis bancaria, el PIB efectivo de los países afectados se encuentra todavía un $10 \%$ por debajo del nivel que tendría el PIB de tendencia que dichos países hubiesen alcanzando en ausencia de la crisis (FMI, 2009d).

\section{La gran crisis financiera de 2007-2009}

En esta sección describiremos el desarrollo de la GCF, a la luz de las características generales de las crisis señaladas previamente. Comenzamos con la caracterización del período de bonanza que precedió a la GCF, para describir luego las tres etapas de la crisis ${ }^{4}$.

${ }^{4}$ Otros observadores han dividido la evolución de la GCF en un número mayor de fases. Por ejemplo, Bank for International Settlements (2009) divide la crónica de la crisis en cinco etapas. 


\section{III.1. Preámbulo: La bonanza}

Tanto el período de bonanza previo a la crisis, así como la crisis propiamente tal, tuvieron grandes similitudes generales con crisis financieras previas, aunque sus condiciones y manifestaciones particulares son idiosincráticas a esta experiencia. El período de auge estuvo marcado por una expansión muy prolongada en EE.UU. después de la recesión provocada por el reventón de la burbuja de las acciones puntocom a comienzos de la década pasada. El creciente optimismo generado por este auge se reflejó en una intensa expansión crediticia y significativos aumentos en los precios de activos financieros e inmobiliarios, que fueron retroalimentando el crecimiento del gasto y del producto.

En el caso de EE.UU., el creciente apetito por riesgo y la innovación financiera llevaron a un explosivo incremento en el crédito de vivienda, beneficiando particularmente a segmentos de la población de alto riesgo, no digna de crédito. La innovación financiera se reflejó en que estos créditos hipotecarios subprime ${ }^{5}$ se empaquetaban de diversas maneras, generando un instrumento financiero estructurado, y luego se vendían over-the-counter (fuera de una bolsa de transacciones formal) a bancos comerciales, bancos de inversión y otros intermediarios financieros, dentro y fuera de EE.UU.

Es importante notar que los créditos hipotecarios no se vendían de manera individual. Si ése hubiera sido el caso, los malos antecedentes - o en algunos casos la ausencia total de documentación creíble- de los créditos habrían asegurado una recepción muy negativa de parte de los compradores potenciales. La agregación de instrumentos financieros es una práctica común para disminuir la exposición al riesgo idiosincrático de cada uno (una implementación de la idea de no poner todos los huevos en la misma canasta), pero crea el problema que analizar cada instrumento individual es costoso, y el comprador de una cartera de instrumentos agregados suele depender de la opinión de terceros sobre la calidad de éstos. En el caso de los créditos hipotecarios, este problema de información se agravó por la manera en que los créditos se

${ }^{5}$ Los créditos hipotecarios subprime son los que se extienden a personas que tienen una mala trayectoria de servicio de sus deudas o no tienen historia previa, por lo cual se conceden usualmente a tasas de interés sustancialmente mayores que las de los créditos hipotecarios extendidos a clientes prime. 
empaquetaron en instrumentos estructurados, como lo eran las $\mathrm{CDO}^{6}$ : el nivel del riesgo del instrumento estructurado dependía de supuestos estadísticos y modelos complejos que sus compradores potenciales no tenían la capacidad de evaluar. La ingeniería financiera, o mejor dicho alquimia financiera, logró mediante este proceso de empaquetamiento y jerarquización de pagos crear instrumentos financieros que obtuvieron clasificaciones de riesgo AAA (la más alta en todo el mercado de renta fija) a partir de préstamos subprime que un acreedor serio hubiera desestimado.

Los compradores de estos instrumentos estructurados eran variados. En algunos casos eran inversionistas que estaban obligados a comprar activos con una clasificación de riesgo muy alta - como fondos de pensiones - pero que preferían hacer una ganancia marginal comprando instrumentos estructurados AAA en vez de activos más tradicionales, como bonos soberanos. En otros casos eran instituciones financieras que pertenecían a las casas matrices de bancos comerciales y bancos de inversión, llamadas conduits o vehículos estructurados de inversión (structured investment vehicles o SIV), que financiaban la compra de estos instrumentos estructurados mediante la emisión de deuda (usualmente en la forma de papel comercial o commercial paper, un tipo de deuda de corto plazo de entre 1 y 270 días, sin respaldo de colateral, que emiten bancos y grandes corporaciones, y que suelen ser adquiridos por fondos mutuos de corto plazo).

Sin embargo, la bonanza económica, el crecimiento del crédito y la burbuja de precios no se limitaron al mercado inmobiliario de EE.UU. Pasó del mercado inmobiliario a otros segmentos del crédito y otras clases de activos financieros, y se extendió más allá de EE.UU. a un conjunto de economías desarrolladas. ¿Cuáles características exhibieron estas economías? Pues bien, alguna combinación de condiciones macroeconómicas muy expansivas, fallas muy serias en la regulación y supervisión financiera, y segmentos financieramente frágiles y mal re-

${ }^{6}$ Collateralized debt obligation: un instrumento financiero que paga a sus dueños en un orden jerárquico, tal que primero se paga a los dueños con mayor rango, y luego a aquellos con menor rango. Si algunos de los componentes del instrumento cesan sus pagos —en este caso, algunos deudores subprime dejan de pagar-, aquellos inversionistas con menor prioridad (que reciben una alta tasa de interés para compensar el riesgo que toman) pierden todo, mientras que aquellos con mayor prioridad (que reciben una baja tasa de interés) no pierden nada. 
gulados del mercado de capitales que intermedian derivados o garantías de créditos hipotecarios (como los government-sponsored enterprises o GSE, Fannie Mae y Freddie Mac, en EE.UU.; las cajas hipotecarias en España; las Landesbanken en Alemania).

La euforia y el creciente apetito por riesgo también se extendieron más allá del crédito hipotecario al crédito de consumo y de empresas en muchas economías desarrolladas, financiando un creciente gasto privado (y, en varias economías, también público), reflejado en elevados déficits en cuenta corriente. Debido a su peso económico, los crecientes déficits en cuenta corriente de EE.UU. llevaron a una preocupación intensa por el desbalance global (es decir, de EE.UU.), cuya contrapartida principal era el creciente superávit en cuenta corriente de China. Ésta constituía, de hecho, la mayor preocupación financiera global en el quinquenio 2002-2006. Cuando nadie hablaba de créditos subprime aún, la próxima crisis se asociaba a la posibilidad que los crecientes flujos de endeudamiento externo de EE.UU. llevasen a un cese repentino de dichos flujos, causando una necesidad de reversión brusca del déficit en cuenta corriente, con la consiguiente devaluación masiva del dólar de EE.UU., una recesión en dicho país y, luego, una recesión mundial derivada de la anterior dado el tamaño de la economía de EE.UU.

Sin embargo, la euforia financiera, el boom del crédito y la explosión de gasto agregado no fueron monopolios de EE.UU. También se dieron en un conjunto reducido pero importante de economías europeas, en particular en Gran Bretaña, Irlanda, Islandia, España, Portugal, Grecia y los países bálticos.

Al mismo tiempo, muchas economías emergentes se encontraban en un período de crecimiento sostenido, sin precedentes históricos en dichas economías. Ese crecimiento, liderado por China, llevó a un aumento sostenido en los precios mundiales de los commodities, reforzando el crecimiento económico de los países emergentes exportadores de commodities. No obstante, en contraste con períodos anteriores de auge de dichos precios, este ciclo de bonanza encontró a las economías emergentes mucho mejor preparadas, fruto de sus reformas macroeconómicas y financieras adoptadas desde los años 1990, que las llevó a ahorrar una parte importante de sus ingresos extraordinarios. Este mayor ahorro externo también contribuyó en el margen a financiar los crecientes desahorros externos de los países industriales mencionados arriba. 


\section{III.2. Fase 1: Turbulencias financieras}

Ni las características de riesgo de los activos estructurados basados en créditos hipotecarios subprime, ni sus garantías hipotecarias, ni el volumen de dichos activos, ni la exposición a estos activos en ningún banco, ya sea directamente o indirectamente a través de sus instituciones financieras laterales, eran de conocimiento de reguladores, gobiernos, bancos centrales e inversores hasta mediados del año 2007. Aunque algunos reguladores, unos pocos analistas y excepcionales inversionistas reconocieron la punta del iceberg, nadie sospechaba su dimensión oculta y sus ramificaciones en segmentos y localizaciones insospechadas del sistema financiero global. Parecido al Titanic en rumbo a la colisión con el gigantesco témpano, el mundo financiero se dirigía en el 2007 con los motores a fondo hacia la GCF, sin sospechar los alcances ni la dimensión del peligro inminente.

La primera etapa de la crisis comenzó con el fin de la burbuja inmobiliaria en EE.UU. El índice Case-Schiller, que mide los cambios en precios de vivienda en las zonas metropolitanas más importantes de EE.UU., indica que éstos aumentaron sostenidamente a nivel nacional desde comienzos de los 90, pero podemos distinguir dos subperíodos distintos. El primero, entre 1992 y 1998, fue caracterizado por aumentos leves en el precio de viviendas (el incremento promedio fue $2,24 \%$ anual, por debajo de la inflación). La burbuja inmobiliaria como tal comenzó en el segundo período, entre 1999 y 2006, en que los precios crecieron a un ritmo acelerado (el incremento promedio fue 10,39\% anual). Si bien la tendencia de precios en alza fue general, el ritmo de incremento en distintas ciudades fue muy dispar: ciudades como Dallas y Denver registraron aumentos totales de alrededor de $40 \%$ entre 2000 y 2006, mientras que otras como Miami y Los Angeles registraron aumentos de aproximadamente $175 \%$ en el mismo período.

El Gráfico No 1 ilustra el fin de la burbuja inmobiliaria. Ésta llegó a su nivel máximo en julio del 2006, pero el deterioro durante el resto del 2006 y comienzos del 2007 fue lento y leve. Los mercados financieros sólo tomaron conciencia plena de los problemas en el mercado inmobiliario en junio del 2007, cuando dos fondos de cobertura manejados por el banco de inversión Bear Stearns, que concentraban sus inversiones en el segmento más riesgoso del mercado inmobiliario, el 
GRÁFICO No 1: IINDICE DE PRECIOS DE VIVIENDA CASE-SCHILLER (CS 20 CITY COMPOSITE INDEX) EN EE.UU., ANTES Y DURANTE LAS TRES FASES DE LA CRISIS, PARA EL PERÍODO 2005-2011 (BASE $100=2000$ )

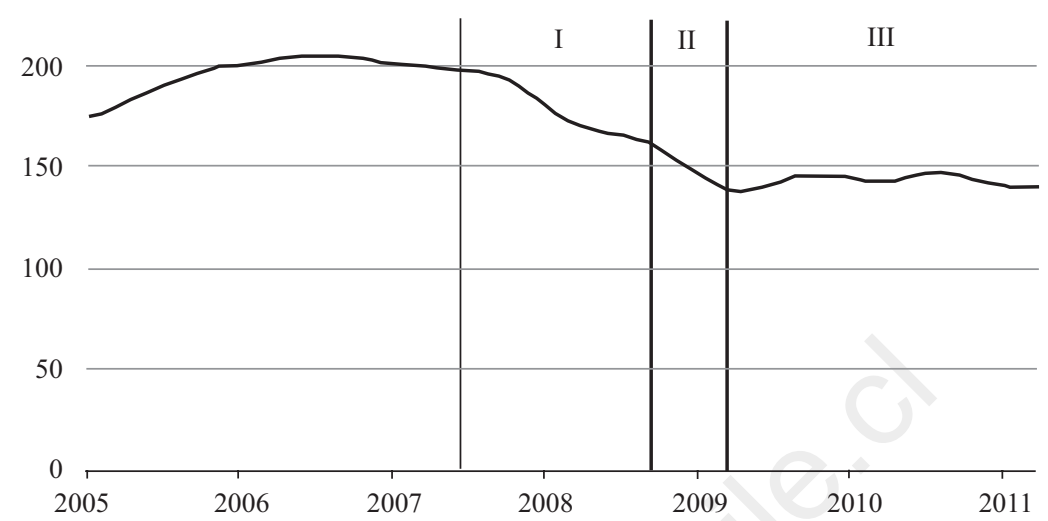

Fuente: Bloomberg.

subprime, colapsaron súbitamente debido al deterioro en el valor de sus activos y las dificultades de acceso a financiamiento que le siguieron.

La quiebra de estos fondos marcó el comienzo de la crisis, actuando como un piedrazo en una laguna: generó olas de incertidumbre y nerviosismo sobre su otrora lisa y llana superficie. Los mercados financieros percibieron un deterioro masivo en el segmento subprime, pero desconocían cuán profundo sería el problema y quiénes estaban expuestos. La complejidad de los instrumentos financieros en que se empaquetaron las hipotecas hizo muy difícil valorarlas en este clima de incertidumbre. Repentinamente el mundo financiero transitó de la confianza plena a la conciencia de su ignorancia, es decir, su desconocimiento de los valores de activos financieros complejos y su falta de información respecto de la exposición a dichos activos de sus contrapartes financieras. Con dicha conciencia aparecieron las primas de riesgo de contraparte en muchas transacciones financieras, bancos comerciales interrelacionados a diario en los mercados de préstamo interbancario overnight y de corto plazo comenzaron a desconfiar de sus pares, exigiendo el pago de crecientes primas de riesgo en dichas transacciones. Reflejando dicha incertidumbre, el sistema financiero comenzó a actuar de una manera más conservadora, restringiendo el volumen y las condiciones de los préstamos que otorgaba a sus clientes: aumentó también 
fuertemente el costo de crédito que se exigía incluso a deudores con la mejor reputación y situación financiera, como ilustra el Gráfico $\mathrm{N}^{\mathrm{o}} 2$.

Los bancos centrales de las principales economías afectadas respondieron rápidamente a este evento, proveyendo a los bancos grandes volúmenes de liquidez. Apenas algunos días después de iniciada dicha provisión de fondos, al 10 de agosto de 2007, el Banco Central Europeo (BCE) y el banco central de EE.UU. (FED) habían inyectado un monto total equivalente a US\$260 mil millones a los sistemas financieros de sus dos economías. Por lo tanto, las primas de riesgo observadas en el Gráfico $\mathrm{N}^{\mathrm{o}} 2$ reflejan la valorización de dicho riesgo, pero ya morigerado por las intervenciones cuantitativas de los respectivos bancos centrales.

Si bien el estímulo monetario alivió la contracción crediticia en alguna medida, las pérdidas de inversiones en instrumentos hipotecarios subprime siguieron aumentando: dos fondos del banco francés BNP Paribas se vieron forzados a detener los retiros por parte de inversionistas en agosto de 2007. Las pérdidas, tanto realizadas como anticipadas, que sufrieron los bancos comerciales, bancos de inversión y fondos mutuos que habían comprado estos instrumentos llevaron a una erosión de su

\section{GRÁFICO No ${ }^{\circ}$ S: SPREADS DE INTERÉS EN BONOS DE EMPRESAS CON CLASIFICACIÓN DE RIESGO AAA Y BBB EN EE.UU., ANTES Y DURANTE LA CRISIS, 2007-2011 (\%)}

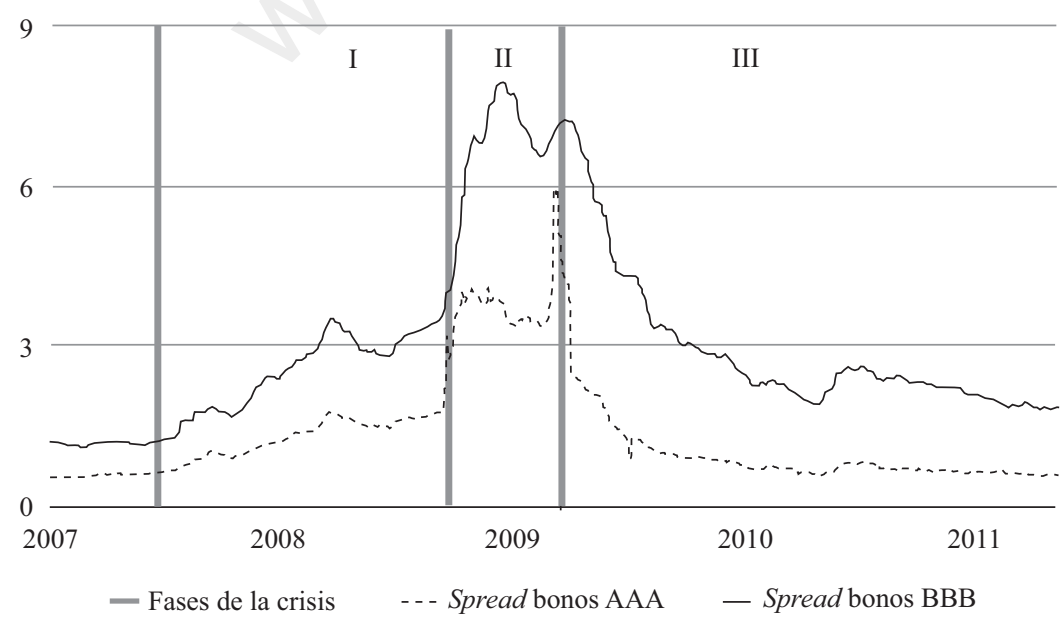

Fuente: Federal Reserve Bank of St. Louis. 
capital y luego de su solvencia. La contracción crediticia, a su vez, comenzaba a causar problemas de liquidez en instituciones financieras no bancarias, que dependen de financiamiento de corto plazo.

Las primeras víctimas de alto perfil de la crisis fueron bancos europeos. Los Landesbanken, bancos de propiedad de estados alemanes, fueron importantes compradores de instrumentos financieros estructurados basados en créditos hipotecarios subprime y sufrieron pérdidas importantes incluso durante la primera fase de la crisis. Sachsen LB colapsó a fines de agosto de 2007 y fue rescatado por uno de sus competidores. Pocos días después, IKB Deutsche Industriebank recibió un rescate por un grupo de bancos alemanes por un total de $€ 3.500$ millones; posteriormente necesitó un rescate adicional, esta vez por parte del estado alemán, por $€ 1.500$ millones adicionales.

La siguiente víctima, a mediados de septiembre de 2007, fue Northern Rock, un banco de tamaño mediano dedicado a créditos hipotecarios del Reino Unido. El modelo de negocios del banco era aumentar su cartera de crédito y sus clientes de manera muy rápida, manteniendo el mínimo posible de nivel de capital y financiando sus actividades con deuda de corto plazo. El ambiente hostil de los mercados financieros causó que el banco se encontrara sin fondos, y llevó a que éste solicitara ayuda del Bank of England, la autoridad monetaria del Reino Unido. Esto fue interpretado por sus depositantes como una señal de severos problemas y se dio la primera corrida bancaria en el país desde 1878. El banco fue nacionalizado posteriormente, en febrero de 2008.

La primera etapa de la crisis se caracterizó por un cambio gradual desde el optimismo al nerviosismo. Los índices accionarios del mundo siguieron aumentando hasta llegar a su valor máximo en octubre de 2007 (véase Gráfico $N^{\circ} 3$ ). Con posterioridad, y a medida que los mercados financieros intentaban estimar la severidad y las consecuencias del deterioro en los precios de bienes raíces y el cese de pagos hipotecarios por parte de los deudores más riesgosos, los inversionistas del mundo iniciaron una huida a instrumentos de calidad (o flight to quality), vale decir, una recomposición de la cartera mundial desde activos considerados riesgosos (como bonos y papeles de deuda de instituciones financieras, bonos soberanos de países emergentes o activos de renta variable en general), volcándose a activos considerados más seguros (como los bonos soberanos de los países desarrollados más grandes, los commodities y, en particular, el oro — véase más adelante Gráfico $\mathrm{N}^{\mathrm{o}} 4$ y su descripción). 
GRÁFICO No 3: $\quad$ ÍNDICES ACCIONARIOS S\&P 500 (EE.UU.; $10=1941-1943$ ) Y MSCI WORLD (ACCIONES MUNDIALES; VALOR BASE $100=$ DICIEMBRE DE 1969) ANTES Y DURANTE LA CRISIS, 2007-2011.

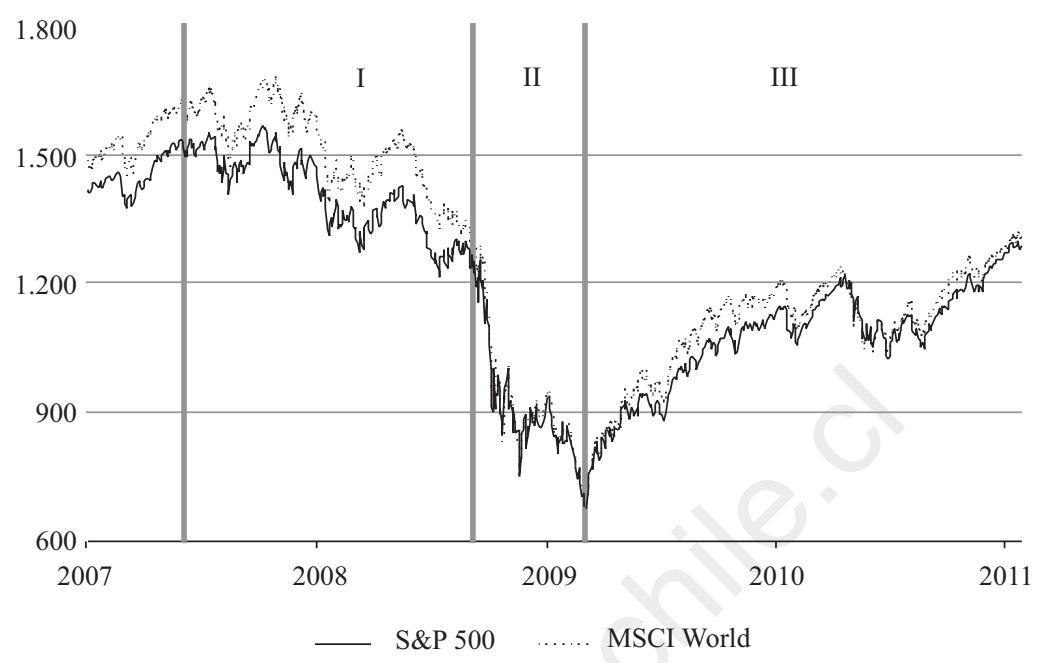

Fuente: Bloomberg.

Sin embargo, connotados economistas y analistas financieros opinaban, incluso a alturas de enero del 2008, que dado el tamaño del segmento subprime relativo al mercado hipotecario total (menos de un $10 \%$ ), el efecto del deterioro del mercado inmobiliario sería leve y que EE.UU. - el país más afectado- no entraría en recesión económica. Y, si bien había presiones sobre el sistema financiero, la mayor preocupación del mercado no era su solvencia sino su vulnerabilidad a que la desconfianza los privara de liquidez. Lo que el mercado desconocía es que los problemas en el mercado hipotecario subprime eran tan sólo la punta de un iceberg: el problema real residía en las distorsiones acumuladas y el nivel de riesgo en el sistema financiero.

La situación no mejoró con el pasar de los meses. Bear Stearns, el banco de inversión más débil de los cinco grandes de Nueva York (en parte a causa de su gran exposición a instrumentos hipotecarios securitizados), perdió la confianza del mercado. Se le cerraron líneas de crédito y no se renovaron los préstamos a corto plazo de los cuales dependía, tal como un banco comercial depende de depósitos. Se vio forzado a pedir un préstamo de emergencia al FED el 14 de marzo de 2008. Los 
mercados interpretaron esta inhabilidad de conseguir financiamiento como una señal de debilidad y sellaron la suerte de la empresa. Dos días más tarde, al borde del colapso, Bear Stearns fue comprado por JP Morgan Chase, con apoyo y garantías explícitas del gobierno americano. Si bien la intervención del gobierno de EE.UU. en la compra de Bear Stearns restauró un cierto grado de confianza, los problemas fundamentales que causaron la caída del banco de inversión no se desvanecieron. Las pérdidas de inversiones inmobiliarias continuaron aumentando, y dado el gran tamaño del mercado inmobiliario americano y la difusión global de los activos hipotecarios de EE.UU., fueron muchas las instituciones financieras afectadas. Lentamente, la preocupación del mercado financiero cambió de naturaleza: dejó de estar centrada en la habilidad de las instituciones financieras para obtener financiamiento, y pasó a estar en si es que, incluso con financiamiento, eran solventes.

Dos tipos de instituciones financieras sufrieron un escrutinio especialmente duro durante esta etapa. El primer tipo fueron las aseguradoras de bonos (conocidos coloquialmente como monoline insurers, o simplemente monoliners). Estas instituciones garantizan el pago de bonos de otras compañías, asumiendo responsabilidad por el pago del capital e intereses si el emisor entra en quiebra. Su modelo de negocios originalmente partió con seguros para bonos municipales, pero hacia el año 2007 eran uno de los partícipes más activos en los mercados de derivados de crédito.

El segundo tipo consistía de las ya mencionadas GSE: Fannie Mae y Freddie Mac, que en conjunto tenían o garantizaban US\$ 5.1 trillion (en terminología americana; billones en terminología española) en hipotecas residenciales, aproximadamente la mitad de todas las hipotecas residenciales vigentes en EE.UU. Prácticamente todo el mercado hipotecario dependía de estas instituciones para facilitar o garantizar transacciones. Cuando el rápido deterioro del mercado inmobiliario puso en duda su solvencia, el gobierno de EE.UU. intentó inicialmente respaldar a ambas empresas con líneas de crédito de emergencia. Cuando se comprobó que esto no era suficiente, el gobierno tomó control formal de ambas empresas el 7 de septiembre de 2008.

La salud de otras compañías financieras importantes siguió deteriorándose durante este período. Lehman Brothers, el más pequeño de los cuatro bancos de inversión sobrevivientes de Nueva York, mantenía 
una razón de deuda a patrimonio altísima, una exposición importante a activos estructurados basados en créditos subprime - que ahora ya se denominaban "activos tóxicos" - y una gran cartera de inversión en bienes raíces. American International Group (AIG), en ese momento la aseguradora más grande del mundo, había vendido pólizas de seguro a favor de un gran número de instrumentos hipotecarios. El mercado tardó en tomar conciencia de los problemas de estas firmas, pero destinó su plena atención a ambas después del rescate de Fannie Mae y Freddie Mac. Las crónicas de la crisis indican que aquellos que conocían la situación de ambas firmas, entre ellos bancos de inversión y el Departamento del Tesoro de EE.UU., tenían dudas que tanto Lehman Brothers como AIG pudieran sobrevivir más allá de octubre.

En esta segunda etapa de la crisis la incertidumbre continuó aumentando. No sólo se expandió el tipo y naturaleza de instituciones en riesgo (compañías aseguradoras, bancos de inversión, los GSE), sino además las intervenciones estatales para calmar los mercados eran impenetrables: no parecía haber un plan en pie, ni una política establecida de qué instituciones recibirían apoyo o bajo qué términos. El efecto flight to quality se intensificó debido a la extraordinaria incertidumbre respecto de la exposición de todas las empresas financieras, bancarias y no bancarias, en EE.UU. y en los centros financieros más importantes del mundo, a activos tóxicos o a derivados de ellos. Los precios de commodities cayeron estrepitosamente a medida que la tesis de "desacoplamiento económico" de los mercados emergentes con respecto al mundo industrial pasó de moda. Los inversionistas compraron los activos financieros más seguros que pudieron encontrar, temiendo lo peor.

\section{III.3. Fase 2: Pánico global y rescate gubernamental}

La quiebra de Lehman Brothers el 15 de septiembre de 2008 marcó abruptamente la transición de las turbulencias financieras al pánico financiero mundial generalizado. El banco de inversión había perdido la confianza del mercado: su modelo de negocios como intermediador financiero estaba naufragando a medida que sus clientes lo abandonaban y sus reservas de liquidez se habían evaporado para cumplir con sucesivas alzas en el colateral que sus contrapartes 
financieras le exigían. Los ejecutivos del banco, que habían resistido su venta hasta hace pocos meses, intentaron desesperadamente encontrar un comprador para la firma, pero las negociaciones con el banco británico Barclays zozobraron cuando las autoridades financieras del Reino Unido se rehusaron a aprobar la fusión sin suficientes garantías de las autoridades americanas, que éstas no estaban dispuestas a otorgar: los rescates previos habían forzado a las autoridades macroeconómicas a desafiar los límites de sus mandatos y el ambiente político no daba para prestar más ayuda. El gobierno de EE.UU., políticamente desgastado por el apoyo que había brindado al sistema financiero en los últimos meses, no tenía ni la convicción de la necesidad ni el apoyo político para intentar un nuevo rescate de una institución financiera. La alternativa elegida el domingo 14 de septiembre fue dejar que Lehman Brothers quebrara el día siguiente.

Esta quiebra fue crucial. Destruyó la creencia implícita de que el gobierno de EE.UU. rescataría a toda y cualquier institución financiera importante. Demostró que incluso las empresas de mayor prestigio y las más interconectadas en el mundo financiero eran vulnerables a la crisis. Resaltó el riesgo de hacer transacciones con contrapartes que estuviesen en una situación financiera débil. Causó importantes pérdidas para los tenedores de bonos de Lehman Brothers, entre ellos fondos mutuos money-market que tenían la promesa implícita de nunca generar pérdidas a sus clientes, llevando a una corrida contra los fondos mutuos.

La quiebra de Lehman amenazó con ser el dominó que tumbaría el sistema financiero entero, en ausencia de una masiva intervención gubernamental. De hecho este evento causó de inmediato un pánico financiero mundial generalizado, paralizando buena parte de los mercados de crédito, de deuda y renta variable. Las consecuencias financieras del pánico generalizado fueron tales que, en las palabras de Persaud (2009):

Muchos de nosotros teníamos la esperanza de que podíamos tomar decisiones, buenas decisiones, en la crisis, en relación a quién rescatábamos y a quién no. Pienso que [...] hemos desarrollado una visión más madura [...] que, en realidad, es imposible hacer el bien en una crisis. El manejo de crisis es muy difícil.

Yo, como muchas otras personas, pensé que podíamos permitir que Lehman Brothers quebrara, que podíamos enviar una 
señal al mercado. Lehman Brothers era uno de los bancos de inversión más pequeños, y no estaba involucrado profundamente en el mercado de vivienda. Y ése fue el pensamiento ese fin de semana, cuando no apareció un comprador de la firma, el 15 de septiembre de 2008.

Lo que descubrimos una semana después fue que, cuando Lehman Brothers cayó, porque fue la primera vez que permitimos que los tenedores de deuda sufrieran pérdidas, los tenedores de deuda no querían extender crédito a nadie más. Y el costo de capital para bancos subió tan rápido el día después de la quiebra de Lehman Brothers que ninguna institución financiera en el Reino Unido, Europa o EE.UU. era solvente. Ni siquiera una. [La traducción es nuestra.]

Se aceleró y extremó la recomposición de la cartera mundial de activos, con el intento de los inversionistas de desprenderse de casi todos los activos del mundo por la adquisición de siete activos considerados como los últimos refugios seguros: liquidez (cash) en dólares, euros y yenes: deuda de los gobiernos de EE.UU., Alemania y Japón; y oro. Mientras los inversionistas intentaban desprenderse de casi todos los activos del mundo (renta variable, renta fija corporativa, renta fija soberana de casi todos los países del mundo, monedas de casi todos los países del mundo, commodities distintos del oro), los precios relativos de todos estos activos caían, mientras que subían los de los siete activos mencionados.

El pánico llevó a la casi completa iliquidez y ausencia de transacciones en muchos mercados financieros de deuda y papeles comerciales. Los precios de los activos no eran registrados o, cuando lo eran producto de las escasas transacciones, reflejaban precios muy bajos, de pánico o de "incendio" (fire sale prices). En los primeros días después del 15 de septiembre, muchos bancos fueron atacados a través del retiro de depósitos. La incertidumbre respecto de la solvencia de los bancos también se vio reflejada en el notable incremento del costo de crédito, incluso para deudores con buena clasificación de riesgo (Gráfico $\mathrm{N}^{\circ} 2$ ). Las bolsas del mundo registraron enormes pérdidas de valor en los siguientes seis meses, porcentualmente los más significativos desde la Gran Depresión (Gráfico No 3). Rusia suspendió la transacción de acciones por dos días. Otra consecuencia del congelamiento de 
los mercados fue el completo cese de la emisión primaria de bonos de baja categoría de riesgo en el mercado de EE.UU. y de muchas otras plazas financieras del mundo entre el 15 de septiembre y el 31 de diciembre de 2008.

Las consecuencias de estos eventos en el sistema financiero fueron nefastas. El 28 de septiembre las autoridades de Bélgica, Holanda y Luxemburgo unieron fuerzas para evitar la quiebra de Fortis, una de las instituciones europeas más importantes en las industrias de bancos y seguros. El día siguiente el gobierno británico nacionalizó a Bradford \& Bingley, un importante banco hipotecario del Reino Unido. Ese mismo día, el gobierno de Islandia anunció la nacionalización de uno de los tres grandes bancos nacionales, Glitnir, y el cuarto banco más grande de los EE.UU., Wachovia, fue adquirido por Citigroup. El Presidente Bush intentó implementar un plan para intervenir y rescatar firmas financieras, pero el plan fue rechazado en el Congreso americano y el índice accionario Dow Jones tuvo la mayor caída, en términos absolutos, en su historia. El día siguiente, el 30 de septiembre, Dexia se convirtió en el siguiente banco europeo en ser rescatado. Dada la importancia del banco a través de fronteras nacionales, al igual que Fortis, se plasmó un acuerdo entre los gobiernos de Bélgica, Francia y Luxemburgo para cofinanciar el rescate.

El comercio internacional había aumentado de manera explosiva en el período previo a la crisis, y esta tendencia se mantuvo durante la primera fase de la crisis (como indica el Gráfico $\mathrm{N}^{\circ} 4$, el valor de importaciones y exportaciones aumentó más de $60 \%$ entre comienzos de 2006 y mediados de 2008). Esto cambió bruscamente durante la segunda fase: el comercio mundial cayó más de $40 \%$ desde su valor máximo, constituyendo la caída más grande de la historia (aún mayor que la que siguió al inicio de la Gran Depresión).

Si bien las estadísticas de exportaciones e importaciones de la OMC sólo están disponibles con un rezago de algunos meses, el mundo tenía buenos indicios de qué estaba ocurriendo con el comercio internacional. El eje derecho del Gráfico $\mathrm{N}^{\mathrm{o}} 4$ muestra la evolución del Baltic Dry Index, un índice compuesto que mide el precio de transporte marítimo de bienes secos alrededor del mundo, que se actualiza diariamente y por ello se usa como indicador líder del comercio mundial. El índice llegó a su nivel histórico máximo en mayo de 2008 a causa de la fuerte demanda por commodities y una escasez de barcos de transporte, pero 
GRÁFICO No 4: VALOR DEL COMERCIO INTERNACIONAL PARA UNA MUESTRA DE 70 PAÍSES $(100=$ ENERO 2006) E ÍNDICE DEL COSTO DE TRANSPORTE INTERNACIONAL MARÍTIMO DE BIENES SECOS (BALTIC DRY INDEX) ANTES Y DURANTE LA CRISIS, 2006-2011

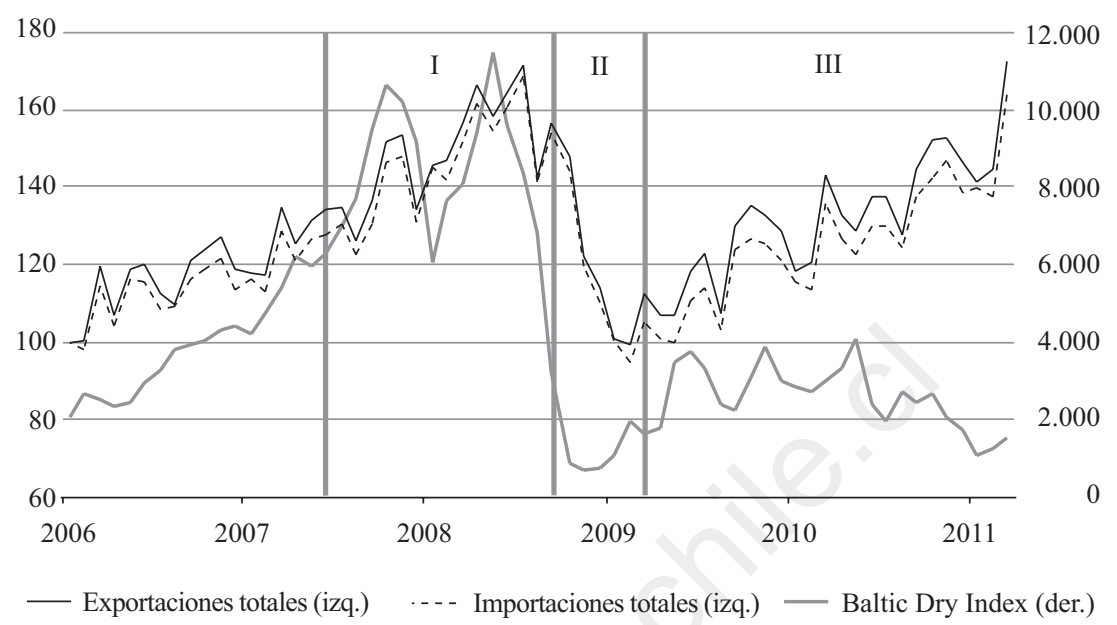

Fuente: Organización Mundial del Comercio, Bloomberg.

cayó de manera estrepitosa en esta segunda fase: en más de $70 \%$ entre mayo y fines de septiembre de 2008 , y más de $90 \%$ entre mayo y fines de octubre de 2008. Esta caída, percibida por el mercado en tiempo real, constituyó uno de los presagios más aterradores de las consecuencias potenciales de la crisis.

Los eventos de fines de septiembre generaron conciencia en los gobiernos y bancos centrales de los países más afectados por la crisis de que se estaba jugando la historia, y uno de los desenlaces posibles hubiese sido una repetición de la Gran Depresión, con sus nefastas consecuencias sobre la actividad y el empleo. En contraste con las medidas erróneas o ausentes tomadas por las autoridades gubernamentales después de octubre de 1929, en esta ocasión se tomaron medidas de emergencia sin precedentes históricos en cuanto a su cobertura, intensidad y rapidez.

Las medidas de gobierno cubrieron una amplia gama de medidas de intervención financiera para normalizar los sistemas financieros y políticas macroeconómicas expansivas para contrarrestar la caída libre del gasto privado y de la actividad económica. Las intervenciones financie- 
ras incluyeron la extensión de garantías sobre los pasivos de instituciones financieras (evitando así las corridas contra dichas instituciones), la compra de activos de instituciones financieras, la extensión de líneas de crédito de emergencia, y las intervenciones y nacionalizaciones de instituciones financieras al borde de la quiebra. Las medidas de emergencia monetaria combinaron el uso del instrumental monetario convencional, consistente en reducir las tasas de interés de política monetaria a niveles cercanos a $0 \%$, con la aplicación de instrumentos no convencionales de relajamiento cuantitativo de la liquidez por los bancos centrales, reflejada en la infusión masiva de dinero de alto poder en las economías más afectadas (especialmente EE.UU., la zona euro, Japón y Gran Bretaña) a través de la adquisición de pasivos privados y públicos, a fin de proveer liquidez en mercados financieros y de crédito que se estaban secando. En lo fiscal, los gobiernos implementaron rápidamente $-\mathrm{y}$ a veces sucesivamente - programas fiscales expansivos.

La intensidad y velocidad en la adopción de las medidas de intervención financiera y de relajamiento monetario y fiscal, así como su coordinación internacional de facto, no tienen precedentes en la historia económica mundial. Nunca antes un número tan grande e importante de gobiernos y bancos centrales, de países afectados directamente e indirectamente por una crisis, desarrollados y emergentes, había tomado, en un plazo tan breve - fundamentalmente entre septiembre de 2008 y enero de 2009- medidas de emergencia económica tan vastas y a tal escala. En opinión nuestra, coincidente con muchos analistas y economistas, fue esta intervención masiva lo que evitó la repetición de una recesión mundial del orden de magnitud de la Gran Depresión.

Más aún, la comunidad internacional de países de gran peso económico, representada por el recientemente formado G-20, se comprometió en su reunión de octubre en Washington, DC, no sólo a adoptar y coordinar dichas reuniones de emergencia, sino a mantener un orden económico internacional abierto al comercio y a los flujos de capitales. También ello contrastó con el nefasto cierre al comercio mundial de bienes y activos, que intensificó la Gran Depresión y redujo el crecimiento de la economía mundial por el siguiente medio siglo.

No obstante las medidas tomadas, las economías desarrolladas sufrieron una importante recesión entre el cuarto trimestre de 2008 y el segundo trimestre de 2009 (Gráfico № 5). Ello arrastró a la economía 
mundial a una recesión, aunque los países en desarrollo siguieron creciendo como grupo ${ }^{7}$. Producto de la disrupción del crédito doméstico e internacional, y de la gran incertidumbre financiera y real, se contrajo muy significativamente la demanda mundial por bienes de inversión y por bienes de consumo durable, lo que llevó a una violenta caída en el comercio internacional de estos bienes, así como de los bienes intermedios y de los commodities. Con ello, la tendencia a la baja que mostraban los precios de los commodities a fines de la primera fase se intensificó, mientras que el precio del oro alcanzaba nuevos niveles récord (Gráfico No 6 ).

GRÁFICO N ${ }^{\circ}$ 5: CRECIMIENTO DEL PIB EN REGIONES Y PAÍSES SELECCIONADOS ANTES Y DURANTE LA CRISIS, 2007-2010 (\% TASA DE CRECIMIENTO SOBRE EL TRIMESTRE EQUIVALENTE DEL AÑO ANTERIOR)

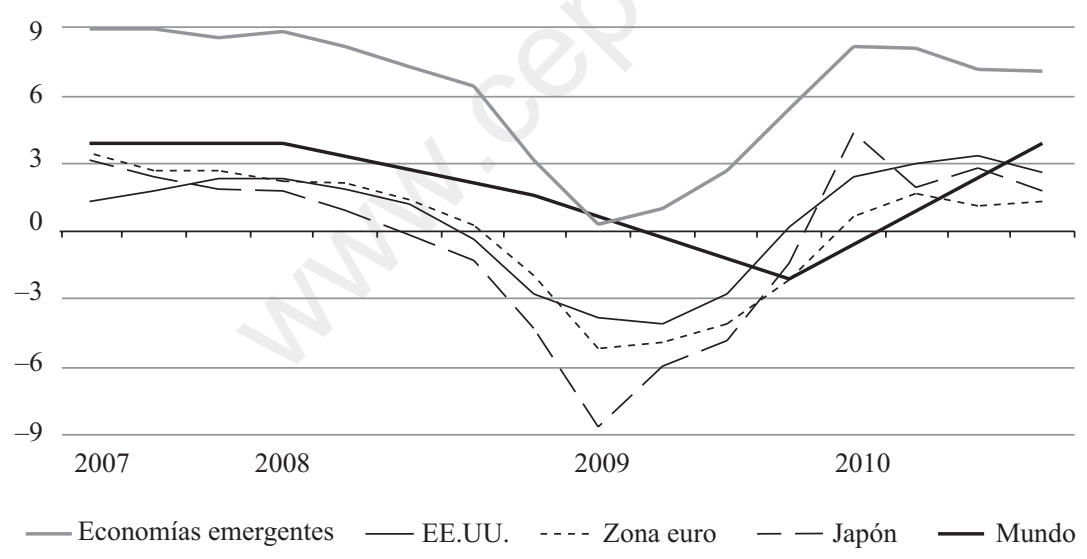

Fuente: Fondo Monetario Internacional.

${ }^{7}$ En el conjunto de países en desarrollo se observaron significativas diferencias regionales. Mientras Asia siguió creciendo, América Latina y el Caribe sufrieron una recesión moderada. Sin embargo, Corbo y Schmidt-Hebbel (2011) muestran que la adopción de mejores políticas permitió a América Latina sortear mucho más exitosamente los efectos de la crisis mundial en 20082009 que cuando tuvo que enfrentar las consecuencias de la crisis asiática en los años 2008-2009. 
GRÁFICO No 6: ÍNDICE S\&P GSCI DE COMMODITIES (100 = ENERO 1970) Y EL PRECIO DEL ORO (US\$ POR ONZA), ANTES Y DURANTE LA CRISIS, 2006-2011

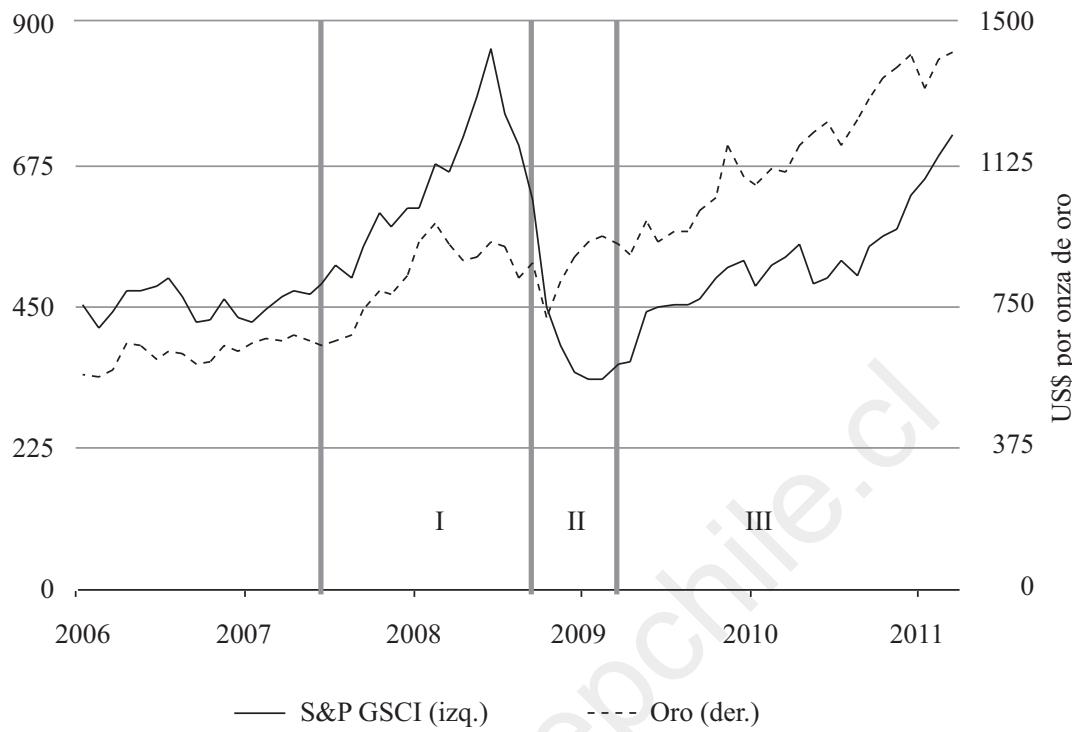

Fuente: Bloomberg.

\section{III.4. Fase 3: Estabilización financiera y recuperación real}

La estabilización de los mercados financieros frenó la espiral de deterioro económico que fue gatillado por la caída de Lehman Brothers, pero sus efectos tomaron tiempo en estabilizar al sistema financiero y la economía. Las garantías otorgadas por todos los gobiernos a "toda institución financiera sistémicamente importante" redujo a partir de noviembre-diciembre de 2008 el riesgo de contraparte en las transacciones financieras, restituyó gradualmente la confianza en pasivos de instituciones financieras, contribuyó a hacer nuevamente líquidos a mercados que se habían secado casi completamente y ayudó a la recuperación de los precios de activos financieros. Sin embargo, el rezago con el que se conocían los datos económicos y el fuerte nivel de incertidumbre en el sistema financiero llevó a que las bolsas mundiales siguieran cayendo y tocaran fondo sólo en marzo del 2009 — casi seis meses después del comienzo de la segunda fase. El comienzo de la fase de estabilización 
financiera y recuperación real, que fue en marzo de 2009, es marcado por la desaparición gradual de este clima de miedo e incertidumbre desatada y la esperanza de que, gracias a las fuertes medidas de intervención económica por parte de las autoridades mundiales, lo peor había efectivamente quedado atrás.

Las recuperaciones financiera y real se reforzaron mutuamente a lo largo de 2009 y 2010. Sin embargo, el crecimiento económico en los países más afectados por la crisis financiera - como EE.UU. y Gran Bretaña - ha sido coherente con el patrón de las recuperaciones de crisis financieras históricas: lento y disparejo, recuperando niveles que distan aún bastante de los que son coherentes con la trayectoria del PIB tendencial previo a la crisis.

Más aún, el costo de las políticas de rescate a la banca y/o políticas fiscales expansivas adoptadas por la mayoría de los países industriales ya se ha hecho evidente en aquellas economías que muestran niveles de alto endeudamiento público y bajo crecimiento. Así, Grecia, Irlanda y Portugal han debido ser rescatadas en 2010-2011 por programas de asistencia crediticia de la Unión Europea y del FMI, a fin de evitar su inminente quiebra. No podemos descartar que otros los sigan. Además, no obstante la recuperación de la fortaleza financiera de muchos bancos e instituciones financieras no bancarias, persisten dudas sobre la fragilidad de instituciones individuales en muchos países.

La crónica de la GCF es consistente con el patrón y las características genéricas de las crisis financieras que dibujamos en la sección anterior. Un ambiente de gran optimismo y disponibilidad de crédito llevó a una burbuja en los mercados inmobiliarios de EE.UU. y otros países. Muchas de las inversiones (compras y construcciones de propiedades) se hacían por motivos especulativos, para luego intentar venderlas a un mayor precio. Muchos de los compradores no tenían los medios para pagar los créditos, pero los bancos (tanto comerciales como hipotecarios) les prestaban dinero de todas maneras. Muchos de los instrumentos financieros en que se empaquetaban estas hipotecas riesgosas se vendían a precios excesivamente altos a inversionistas alrededor del mundo. Apoyada en fallas masivas de políticas financieras y macroeconómicas, la euforia derivó en exceso. Una vez que la euforia terminó y el público se dio cuenta de todos estos errores - de que el precio de viviendas podía comenzar a caer en vez de subir continuamente, que muchas de las personas que habían comprado casas no eran 
capaces de pagar las hipotecas y que nadie sabía quién iba a sufrir las pérdidas asociadas - , se dio inició a la incertidumbre, a la huida a la calidad y a la reversión en los precios de activos. La quiebra de Lehman Brothers gatilló el pánico generalizado en el sistema financiero internacional, paralizando los mercados de crédito y causando la recesión más profunda en tiempos de paz desde la Gran Depresión. Sólo la oportunidad, intensidad, extensión y coordinación de rescate financiero y apoyo macroeconómico por los gobiernos más grandes en toda la historia evitaron que esta Gran Recesión se transformase en una Gran Depresión.

\section{III.5. Fase 4: El deterioro de la crisis de deuda soberana en Europa (en pleno desarrollo)}

La crisis ha tomado una nueva dimensión en los últimos meses con la profundización de la crisis de deuda soberana en Europa. Los problemas comenzaron en mayo del año 2010 con una reevaluación de los mercados del riesgo soberano de Grecia que se gatilló, en parte, por la revelación de que sus cuentas fiscales habían subestimado el valor de su déficit, y por la percepción de que el respaldo implícito de la zona euro a Grecia y a otros países que pudieran tener problemas, era menor que lo anticipado. Pero la crisis tomó una nueva dimensión cuando los mercados se comenzaron a preocupar de la dinámica de la deuda de Italia y sus eventuales problemas de solvencia en un escenario de crecimiento muy débil. También ha incidido la incapacidad del gobierno italiano, a diferencia del de España, de articular reformas que ayuden a consolidar la solvencia fiscal y acelerar el crecimiento. Dada la dinámica que ha tomado la crisis, se van a necesitar acciones mucho más decididas para que mejoren su solvencia fiscal y retomen el crecimiento los países cuestionados por los mercados, esto es Grecia, Portugal, Italia y, en menor medida, Irlanda y España, y un compromiso más agresivo de los países más solventes de la zona con el apoyo a los gobiernos que son solventes y que emprendan reformas que fortalezcan sus solvencias. De no detenerse esta peligrosa dinámica, no se puede descartar una crisis en la zona euro con consecuencias para su sistema monetario y para su sistema bancario, para su crecimiento y para el sistema financiero mundial y el crecimiento mundial. Este deterioro encuentra a los países avanzados con menos capacidad de maniobra para intentar reducir sus efectos dado que la solvencia fiscal es más débil por la misma crisis y porque, con la excepción 
de la zona euro, las tasas de interés de política ya son cercanas a cero. En el caso de los Estados Unidos tampoco ayudan las malas relaciones entre el ejecutivo y el Congreso, lo que hace difícil la aprobación de cualquier programa de estímulo.

En sus rasgos generales, la GCF fue similar a otras crisis financieras de la historia. Sin embargo, sus causas y manifestaciones específicas son idiosincráticas a ella. Por eso vale la pena indagar más profundamente en dichas causas y catalogarlas una a una en detalle.

Las siguientes secciones agrupan las distintas causas en tres categorías esenciales: aquellas que crearon la oportunidad para que se diera una crisis financiera, aquellas que crearon la voluntad para aprovecharla, y finalmente aquellas que permitieron que el sistema de regulación y supervisión financiera — creados justamente para evitar catástrofes de este tipo- fallara.

\section{Oportunidad: Las condiciones macroeconómicas}

Como discutimos en la segunda sección, los pánicos y las crisis financieras suelen ser precedidos por una rápida expansión del crédito. Ésta crea un ambiente favorable para la especulación y la formación de burbujas financieras. En este sentido, el ambiente macroeconómico en los años previos a la crisis fue extremadamente favorable al desarrollo de la crisis posterior.

Paradójicamente, la oportunidad para que surgiera una crisis en el centro financiero mundial (los países industriales y, particularmente, EE.UU. y Gran Bretaña) tiene que ver con la prudencia y moderación de la periferia (los países en desarrollo). Las crisis que sufrieron distintas economías emergentes durante las décadas de 1980 y 1990 (la crisis de deuda latinoamericana de 1982-1985, las crisis mexicana de 1994, la crisis asiática de 1997-1998, la crisis rusa de 1998 y la crisis brasilera de 1999) llevaron a que éstas adoptaran políticas más prudentes a partir de fines de los 1990. El mejor ejemplo de este cambio es el comportamiento de las economías de Asia emergente. Su modelo tradicional de desarrollo había sido uno en que las grandes compañías locales tenían acceso a crédito a un costo muy bajo debido a los subsidios o garantías estatales. Esto condujo a que las compañías locales sobreinvirtieran en malos proyectos. Estos subsidios fueron desmantelados, en gran medida, después de la crisis asiática, llevando a una reducción en la 
inversión local (sin mayores efectos para el crecimiento económico), mientras que el ahorro nacional aumentó, lo que se vio reflejado en crecientes superávits en cuenta corriente. En China, la subvaluación cambiaria y las restricciones a la entrada de capitales incrementaron aún más los superávits en cuenta corriente. En el caso de los países exportadores de materias primas, el manejo prudente de la extraordinaria bonanza de precios de commodities que se desarrolló a partir de 20022003 los llevó a ahorrar una buena parte de dicha bonanza en activos externos. Como resultado de los factores anteriores, el mundo emergente fue acumulando significativos ahorros que excedían con creces a la inversión local. Una fracción creciente de estos ahorros se invirtió en el extranjero, adquiriendo instrumentos financieros de alta calidad y seguridad; en particular, deuda pública de EE.UU. A nivel mundial se observa también un aumento en la tasas de ahorro, desde $20,9 \%$ en 2003 a 24,4\% en 2007. Esta creciente oferta de ahorro mundial llevó a una caída en las tasas reales de interés, que empujó al alza los precios de activos financieros y a su vez indujo a los inversionistas a buscar activos de mayor riesgo y retorno. Este aumento en el apetito por riesgo llevó a que cayeran las primas de riesgo de muchas clases de activos financieros riesgosos.

Este exceso de ahorro no fue el único factor que disminuyó las primas por riesgo. El extraordinario éxito en estabilizar las economías del mundo, que redujo y estabilizó las tasas de inflación en niveles muy bajos de un solo dígito, estuvo asociado a un crecimiento elevado y compartido entre países desarrollados y en desarrollo. De hecho, las economías emergentes —en las cuales los BRIC eran paradigmáticoscontribuían cada vez más al crecimiento de la economía mundial, de la mano de un comercio mundial que se expandía al doble de la tasa de crecimiento del PIB mundial.

La caída en volatilidad macroeconómica, denominada la "Gran Moderación", y el elevado crecimiento económico global, producto de la integración global de mercados de bienes y capitales, se consideraba un logro permanente, induciendo un optimismo generalizado sobre las perspectivas futuras. En este ambiente de percepción de cambio estructural y bonanza se instaló la percepción de que las primas por riesgo habían disminuido permanentemente. Ello explica, más que en muchos eventos previos de bonanza, un crecimiento desmedido del crédito que, asociado a un mayor apetito por riesgo, iba dirigido hacia proyectos y 
segmentos más riesgosos, como los deudores hipotecarios subprime en EE.UU. Ello fue propicio para el desarrollo de burbujas de precios, particularmente de aquellos activos respecto de los cuales las percepciones de riesgo se habían modificado más fuertemente $-\mathrm{y}$, a posteriori, más equivocadamente.

Por el otro lado, la economía mundial como un todo es un sistema cerrado. Esto quiere decir que si efectivamente hubo un desequilibrio importante, como establecimos en la sección anterior - la existencia de un fuerte exceso de ahorro que generó un fuerte aumento del crédito- - debe haber habido un desequilibrio de la misma magnitud en endeudamiento. Es decir, se necesitan dos para bailar el tango, y los países industriales fueron un compañero de baile cómplice.

El colapso de la burbuja de acciones puntocom el 2000 y la recesión que le siguió el año 2001 generaron preocupación por un escenario deflacionario al estilo de Japón. En respuesta, la autoridad monetaria de EE.UU. implementó una política monetaria expansiva, manteniendo la tasa nominal de corto plazo baja, y comprometiéndose a mantenerla en un nivel muy bajo por un período prolongado. El bajo costo del crédito de corto plazo, unido a problemas de incentivos en la industria financiera que crearon fallas de mercado, llevaron a un fuerte aumento en el precio de activos y a condiciones financieras muy favorables (Obstfeld y Rogoff 2009, Bean et al. 2010).

Taylor (2008 y 2009a) sugiere que parte importante de la culpa de esta burbuja inmobiliaria corresponde a las políticas monetarias y fiscales de algunos países desarrollados, y específicamente a las de EE.U.U. La acusación es que la política monetaria expansiva del FED exacerbó la expansión crediticia en la economía e impulsó el nivel de endeudamiento que condujo a la crisis financiera. Bernanke (2010) presenta evidencia de que este efecto fue relativamente modesto. Más aún, en el caso del Reino Unido, la tasa de política monetaria estuvo por encima de la sugerida por la regla de Taylor y tanto el nivel de endeudamiento como los precios del mercado inmobiliario tuvieron una de las mayores alzas a nivel internacional (Bean et al., 2010). Finalmente, Svensson (2010) señala que durante la época en que las autoridades monetarias mantuvieron una tasa de política expansiva había temores justificados de que la economía americana pudiera caer en una trampa de liquidez deflacionaria al estilo de Japón. Esta preocupación —que escapa a las recomendaciones más bien mecánicas de una regla 
de Taylor - sugería un fuerte estímulo monetario. Más aún, Svensson señala que se hubiera requerido una política monetaria fuertemente contractiva (lo suficiente para crear una recesión) para frenar la burbuja inmobiliaria.

Considerando que la influencia directa de la política monetaria - que afecta la tasa de interés de corto plazo - en las tasas hipotecarias - que suelen ser de muy largo plazo- es menor, es difícil concluir que la política monetaria tuvo un rol primario en causar la GCF. Sin embargo, los efectos indirectos de una política monetaria expansiva en el sistema financiero son muchos, y algunos de ellos son relevantes. Por ejemplo, las tasas de interés a las que se financiaban SIV y conduits en el mercado de commercial paper, dependían de manera importante de las tasas fijadas por el FED y el BCE, y eran estas instituciones las que financiaron muchas de las hipotecas subprime, en última instancia. De otra parte, se ha argumentado también que las bajas tasas de interés promovieron la generación de desbalances financieros y aumentaron el riesgo de un colapso más adelante en el precio de activos (BIS, 2010).

El caso de la política fiscal es similarmente complejo. La evidencia indica que EE.UU., Alemania, Francia y el Reino Unido todos tuvieron déficits fiscales durante el período 2002-2007, de alrededor de $3 \%$ del PIB en promedio, y que estos déficits coincidieron con déficits de cuenta corriente de una magnitud similar. Mantener déficits fiscales sistemáticamente a través del tiempo es imprudente, y vale recordar que en el caso de EE.UU. en particular el presupuesto estuvo equilibrado hasta comienzos del siglo XXI, y su déficit tuvo relación con mantener dos guerras e implementar una reforma tributaria que redujo significativamente los ingresos fiscales. El Gráfico $\mathrm{N}^{\mathrm{o}} 7$ ilustra el balance del gobierno general (después del pago de intereses) de algunos de los países desarrollados más importantes durante el período relevante:

Si bien como porcentaje de su producto el nivel de estos déficits era moderado, en términos absolutos representaban montos importantes. El Gráfico $\mathrm{N}^{\mathrm{o}} 8$ ilustra el balance de la cuenta corriente para los países con mayor peso a nivel mundial.

En último término todo déficit de cuenta corriente es la suma del déficit (o superávit) privado y el público. En el caso de EE.UU. podemos observar que ambos sectores (el privado y el público) estuvieron en déficit: el déficit de promedio de cuenta corriente para 2002-2007 fue 
GRÁFICO No 7: BALANCE ESTRUCTURAL DEL GOBIERNO GENERAL (\% DEL PIB)

\begin{tabular}{llllllllll}
2001 & 2002 & 2003 & 2004 & 2005 & 2006 & 2007 & 2008 & 2009 & 2010 \\
\hline
\end{tabular}

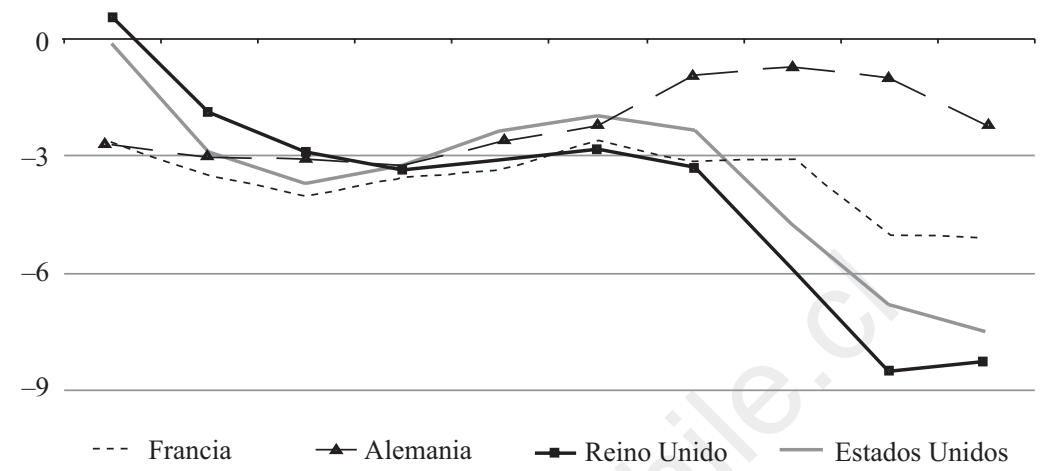

Fuente: FMI, World Economic Outlook Database, abril de 2011.

GRÁFICO No ${ }^{\circ}$ : BALANCE DE CUENTA CORRIENTE A NIVEL MUNDIAL (US\$ MILES DE MILLONES)

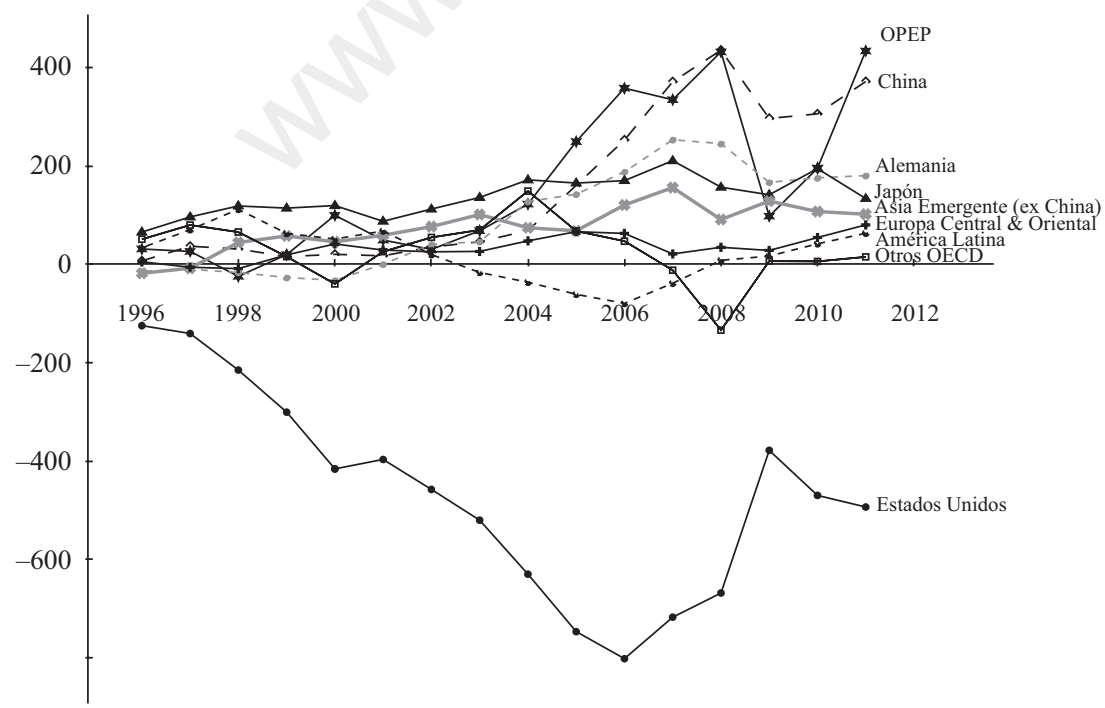

Fuente: FMI, World Economic Outlook Database, abril de 2011. 
$5,2 \%$ del PIB, mientras que el endeudamiento neto del gobierno general de EE.UU. fue 3,52\% del PIB, en promedio, para el mismo período. En el caso del sector privado, esto obedeció a un aumento en el consumo más allá del aumento de los ingresos. El sector público, por su parte, permitió un importante deterioro en sus cuentas fiscales. Esta expansión del gasto estimuló la economía y apuntaló el aumento en los precios de activos —entre ellos los activos inmobiliarios.

Aunque ningún factor fue suficiente por sí sólo para desatar la crisis, la combinación de una política monetaria sobreexpansiva, la estabilidad y el optimismo generado por la Gran Moderación, y una política fiscal expansiva en el mundo desarrollado contribuyeron a crear un ambiente propicio para burbujas en precios de activos. Las políticas monetaria y fiscal de muchos países centrales —incluyendo EE.UU., Gran Bretaña y España - fueron procíclicas, profundizando la toma de riesgo, el incremento del crédito, el aumento del gasto privado y la expansión cíclica en 2003-2007. Esto contrasta con el caso de otros países industriales que tuvieron un manejo más prudente - entre ellos Alemania y los países escandinavos-, que aprovecharon las condiciones favorables para realizar ajustes. En este sentido, las políticas de parte importante del mundo desarrollado actuaron como un agente facilitador para que se diera la crisis más adelante.

\section{Voluntad: Las distorsiones en el sistema financiero}

El sistema financiero ha cambiado dramáticamente en las últimas cuatro décadas desde el fin del acuerdo monetario Bretton-Woods. El capital ha adquirido la posibilidad de moverse libremente a nivel internacional y la regulación que mantenía a la industria financiera encadenada y poco competitiva se ha desmantelado. Como resultado, el sistema financiero ha crecido en tamaño y complejidad para convertirse en algo inimaginable para aquellos que conocían los dóciles mercados de capitales de la década de los 60 .

Esta transformación del sistema financiero internacional ha tenido efectos también en las fallas y defectos que éste presenta. En esta sección analizaremos las distintas fallas de mercado que incidieron en la gran crisis financiera, tanto antiguas como nuevas. 


\section{V.1. Miopía de desastres (disaster myopia)}

Hemos discutido en las secciones anteriores cómo los pánicos financieros (que a su vez conducen a crisis) suelen ser precedidos por un ambiente de optimismo, euforia y exceso. Éste es un patrón recurrente que, según Kindleberger (2005), no ha cambiado en cientos de años y que Keynes lo describió muy bien en su Teoría General. ¿Por qué ocurre?

La investigación en la psicología y los métodos de decisión humanos ha encontrado que los seres humanos usan principios heurísticos para simplificar y calcular rápidamente temas complejos, como puede ser evaluar la probabilidad de un evento o hacer predicciones. Estos algoritmos son rápidos y útiles — la demostración está en la velocidad con que una persona puede hacer estimaciones y predicciones incluso para temas que no entiende de lleno- pero están sujetos a errores sistemáticos. Esto se presenta en detalle en Kahneman, Slovic y Tversky (1982), y se aplica al tema de crisis financieras en Guttentag y Herring (1984). Miopía de desastres es un término que se refiere a un error sistemático en particular de este proceso: los seres humanos tienen una marcada tendencia a subestimar la probabilidad de que ocurran eventos poco comunes, sin importar cuán catastróficas sean sus consecuencias.

La marca de esta falla está presente tanto en el patrón tradicional de una crisis como en la crónica de la gran crisis financiera. La célebre frase "this time is different", la expresión de que la experiencia de crisis anteriores no es aplicable a esta bonanza financiera, y que la probabilidad de que ocurra un desastre es virtualmente cero y por lo tanto el futuro seguirá siendo tan benévolo como el presente, es quizás la evidencia histórica más fuerte de nuestra debilidad en este sentido. Herring (1999) explica este comportamiento de manera elegante al incorporar la idea de sesgo muestral: el horizonte con que el ser humano alimenta su algoritmo de predicción es limitado, y después de largos períodos de estabilidad tenemos la tendencia a asumir de manera implícita que el mundo es estable, y que la ausencia de desastres en los últimos años implica que éstos simplemente no ocurren. Esto lleva al público general a subestimar el riesgo de problemas y solicitar cantidades imprudentes de deuda, haciendo al sistema financiero más frágil, hasta que el desastre no anticipado lo conduzca al colapso. Esta explicación sirve como una justificación conductual para la hipótesis de inestabilidad financiera de Minsky (1986): son funcionalmente idénticas. 
Otro autor reciente que discute esta falla es Taleb (2007), el cual propone que las personas son incapaces de prever eventos de baja probabilidad pero de alto impacto (los popularizados black swans) ex ante, y en su análisis ex post los omiten de sus muestras y modelos al explicarlos de manera histórica y catalogarlos como outliers o eventos excepcionales que no se repetirán. Akerlof y Shiller (2009) también contribuyen a esta línea de pensamiento.

Una primera falla que lleva a las personas y empresas a "aprovechar" la oportunidad presentada por la abundante disponibilidad de crédito para tomar decisiones que, después del hecho, reconocemos como excesivas e imprudentes, entonces, es una falla del método de pensamiento y estimación del ser humano. En la crisis reciente observamos esta falla en las creencias y acciones del público general (había una creencia casi universal de que los precios de vivienda en EE.UU. no podían caer, llevando a compras especulativas), de las instituciones financieras y sus supervisores (el uso de supuestos errados de valoración de inversiones, modelos de valoración que no consideraban escenarios de riesgo de este tipo, fe ciega en la disponibilidad de mercados de crédito al por mayor) e incluso de empresas no financieras (el uso de modelos de negocios que no podían resistir una crisis o disrupción en el sistema de crédito).

\section{V.2. Problemas de agencia}

La teoría de gobierno corporativo usa dos herramientas para alinear los intereses de los dueños de una compañía con aquellos de los ejecutivos encargados de administrar la compañía. La primera es contratar a personal independiente que evalúe a los administradores, como pueden ser directores, auditores, consultores, o abogados. La segunda es remunerar a los administradores según su desempeño: dar mayores recompensas cuando los resultados que obtienen son buenos para los dueños.

Desafortunadamente, ambas herramientas pueden fallar. Monitores externos no pueden hacer su trabajo si desconocen cómo funciona el negocio (información asimétrica), por ejemplo, o si no reciben la información adecuada. Y si bien el principio de pagarle más a un agente 
cuando hace un buen trabajo es razonable, el incentivo puede llevar a que el administrador tome un nivel excesivo de riesgo ${ }^{8}$.

Ambas condiciones de falla se dieron en la Gran Crisis Financiera. Con respecto a la primera falla, la información que el mercado y los monitores externos tenían sobre la actividad y salud de muchas instituciones financieras era insuficiente y engañosa: era una práctica común entre los bancos de inversiones el mantener grandes inversiones riesgosas fuera de los estados financieros, por ejemplo. Más aún, la complejidad de las operaciones y los instrumentos con que estas compañías trabajaban hacía difícil evaluar los errores (accidentales o voluntarios) en la valoración de sus activos. En la práctica, los directores de empresas financieras no eran capaces de entender qué estaba ocurriendo en sus propias compañías. Esta situación era particularmente grave porque la junta de directores de la empresa era la principal línea de defensa en contra de la adopción de modelos de riesgo y estrategias de negocio imprudentes. Una forma de atenuar estos riesgos es un uso más activo de parte de los directorios de informes externos especializados en materias como evaluación de riesgos y de los estados financieros.

Con respecto a la segunda falla, el problema de incentivos asimétricos se agravó por cláusulas contractuales nefastas como los golden parachutes: la promesa de pagar grandes cantidades de dinero a altos ejecutivos cuando éstos dejasen de trabajar en la empresa. Estas promesas no eran inusuales en la industria financiera, y los montos comprometidos eran altísimos. En la práctica, no podían perder: si una jugada arriesgada salía bien, eran recompensados de manera generosa. Si la jugada arriesgada salía mal, salían de la empresa y eran recompensados de manera generosa.

Es importante notar que el segundo problema no estaba limitado sólo al alto mando de la industria financiera. El ambiente en el mundo financiero es brutalmente competitivo y tanto la remuneración como las oportunidades de ascender están ligadas a cuánto dinero una persona genera. Sin embargo, los mercados son volátiles e impredecibles y no

${ }^{8}$ Desde la perspectiva del agente, por un lado, si le va bien, gana mucho dinero; por el otro lado, si le va mal, no gana el dinero y cambia de trabajo.

No sólo es el incentivo asimétrico; la naturaleza corporativa de una compañía hace que sea óptimo tomar un alto nivel de riesgo. En términos financieros, el patrimonio es una opción sobre el valor de los activos de la firma, y el valor de una opción aumenta con el nivel de riesgo. 
hay maneras seguras de generar ganancias. Incluso si hay estrategias que generen buenas utilidades en el largo plazo, éstas no suelen dar buenos resultados a corto plazo (que es lo que más se premia). Esto crea los incentivos para que los miembros más imaginativos del sistema hagan trampa: se enfoquen en obtener fuertes ganancias de corto plazo en promedio, pero sujetas a fuertes riesgos que no son inmediatamente evidentes a sus superiores. Este marco de análisis es capaz de explicar algunas de las peculiaridades del sistema financiero antes de la crisis, como el alto nivel de apalancamiento financiero o la popularidad de instrumentos financieros complejos (sus riesgos eran difíciles de evaluar) y lo común que eran estructuras de seguros: el cobro de primas sustanciales hoy, a cambio de la posibilidad remota de tener que hacer un pago sustancial en el futuro en caso de un desastre.

Podemos aseverar, entonces, que los problemas de agencia contribuyeron a crear la voluntad para aprovechar la abundancia de crédito para tomar un nivel excesivo de deuda, y a seguir estrategias de negocios imprudentemente riesgosas.

\section{V.3. Complejidad}

El sistema financiero se ha vuelto más complejo con el pasar de los años. Las instituciones financieras al crecer en tamaño han adoptado estructuras corporativas más enmarañadas. El uso de tecnologías de la información y transacciones electrónicas ha permitido la adopción de estrategias de negocios más complejas y de mayor tamaño. A medida que ha aumentado el acceso a instrumentos financieros tradicionales, como acciones y bonos, los precios de intermediación que un broker (un agente que compra o vende activos en beneficio de otros) puede cobrar han disminuido, y por ende ha aumentado el interés en crear instrumentos hechos a la medida para clientes, llenos de provisiones y condiciones especiales.

Desafortunadamente, la complejidad de un sistema aumenta el costo de procesar su información. En un sistema no lineal (como seguramente lo son la realidad y el sistema financiero), un aumento en el nivel de complejidad hace que el futuro sea exponencialmente más difícil de predecir. Dado que, como discutimos en la segunda sección, los precios financieros dependen de nuestra habilidad de generar expectativas y predicciones del futuro, debiera ser evidente por qué esto 
es problemático: la complejidad agrava la incertidumbre y los pánicos. En efecto, Caballero y Simsek (2009) plantean que un pánico financiero es causado por un aumento repentino de la complejidad del sistema, creando un ambiente que los economistas denominan de incertidumbre knightiana (para la cual no sabemos siquiera las reglas del juego).

Desde una perspectiva económica, si bien instrumentos y estructuras más complejas pueden tener ventajas sobre sus contrapartes más simples, ellos generan externalidades negativas para el sistema financiero. En primer lugar, agravan los problemas de agencia: se hace más difícil para los monitores externos entender qué está ocurriendo dentro de la empresa, y por ende limitan su habilidad de diagnosticar problemas. En segundo lugar, hacen al sistema más vulnerable a shocks sistémicos: como Caballero y Simsek (2009) sugieren, un sistema más complejo es un sistema más difícil de entender y por ende más vulnerable a pánicos financieros. En tercer lugar, instrumentos y estructuras más complejas tienen más espacio para cumplir con la letra de la ley regulatoria al mismo tiempo que evaden su espíritu, facilitando el arbitraje regulatorio.

La creciente complejidad del sistema financiero, entonces, ayudó a esconder los riesgos verdaderos que distintas instituciones estaban asumiendo. Es importante hacer notar que prácticamente muchas de las instituciones que colapsaron durante la segunda y tercera etapa de la crisis - Bear Stearns, Fannie Mae y Freddie Mac, AIG, Lehman Brothers - abusaron de esta falla de una manera u otra, sea escondiendo inversiones importantes fuera de sus estados financieros o asumiendo contratos con riesgos difíciles de evaluar. También permitió disfrazar instrumentos financieros respaldados con hipotecas subprime precarias y riesgosas como activos seguros, que muchas instituciones conservadoras compraron. Finalmente, agravó el pánico financiero causado por la quiebra de Lehman Brothers, generando una contracción de crédito brutal, cuyo igual no habíamos visto en más de 70 años.

\section{V.4. Riesgo moral (moral hazard)}

Otra distorsión importante que llevó a esta crisis —y que está detrás de muchas crisis financieras- es el riesgo moral: el incentivo a tomar niveles excesivos de riesgo a causa de las garantías y apoyo estatal que se otorgan en tiempos de crisis. 
Como discutimos anteriormente, la naturaleza del sistema financiero lo hace vulnerable a pánicos y crisis de confianza, y es posible que la quiebra de tan sólo una institución le haga un daño severo a todo el sistema, como ocurrió con Lehman Brothers. Las instituciones cuya quiebra tendría este efecto son generalmente conocidas como "sistémicas" o "fuentes de riesgo sistémico". Como es deseable para la estabilidad del sistema financiero y de la economía el que las empresas sistémicas sobrevivan, éstas saben que contarán con apoyo estatal en caso de una crisis. De la misma manera, la garantía estatal de depósitos con la que cuentan los bancos lleva a que los depositantes (por lo menos en la medida que sus depósitos no excedan el monto límite garantizado) no se preocupen de la calidad de los créditos y la solvencia de sus bancos. Ambos efectos crean el incentivo para que instituciones financieras sistémicas y aquellas que no lo son pero cuentan con acceso a garantías estatales de algún tipo, tomen más riesgo que el habitual.

En el caso de la GCF, si hubo alguna duda de que las instituciones sistémicas recibirían apoyo estatal, ésta se disipó en las semanas posteriores a la quiebra de Lehman Brothers, cuando los gobiernos extendieron garantías generalizadas a los intermediarios financieros. Una forma de acotar este riesgo es separar las actividades bancarias propiamente tales de las actividades de inversión, la propuesta Volker, o la propuesta de la autoridad inglesa de construir murallas chinas al interior de una misma institución entre las actividades bancarias y las de inversión y con mayores requerimientos de capital para la actividad de inversión.

\section{V.5. Otras distorsiones}

Las cuatro fallas de mercado que señalamos anteriormente fueron, a nuestro juicio, las más importantes para explicar la Gran Crisis Financiera. Pero no fueron las únicas; en lo que sigue nos referiremos a otras dos.

Una distorsión de menor orden fue el uso de modelos de riesgo con fallas estructurales. Destaca entre éstos Value-at-Risk (VaR), un modelo estadístico que intenta predecir cuál es la mayor pérdida que una empresa sufrirá en el futuro basado en el comportamiento estadís- 
tico de los precios pasados, que se ha convertido en la herramienta más aceptada de medición de riesgo financiero.

Desafortunadamente, el método fue concebido para medir el riesgo que una institución encara día a día, y no es apto para juzgar la aceptabilidad o nivel de peligro de una estrategia de negocios a largo plazo - que fue, en parte, lo que ocurrió. Al ser un modelo conocido y respetado que arrojaba un número objetivo y fácil de entender, a diferencia de las opiniones más difusas de un risk manager profesional (un experto que evalúa el riesgo de los negocios en que la firma participa), los resultados de estos modelos primaron por sobre el juicio más sutil y matizado de profesionales con experiencia. Por lo demás, el rol de un risk manager es antagónico al de un alto ejecutivo que tiene el incentivo para adoptar estrategias riesgosas para maximizar su remuneración en el corto plazo. El resultado fue que el sistema financiero en general dependió demasiado de este modelo - el cual es una buena herramienta para propósitos menos ambiciosos - y actuó con sorpresa cuando, durante la crisis, la realidad fue brutalmente distinta. Cuando profesionales financieros respetados dicen públicamente que "vimos movimientos de precios que correspondían a 25 desviaciones estándares", varios días seguidos", es tiempo de pensar cuidadosamente si la herramienta que están usando para medir el riesgo es apropiada.

Finalmente, una segunda distorsión de menor impacto fue la dependencia del mercado (e incluso de la regulación financiera) en los juicios y modelos creados por empresas que tenían conflictos de interés. A los bancos se les permitía crear sus propios modelos de VaR, usando los supuestos que ellos estimaran convenientes para determinar sus propios requerimientos de capital. Todo el sistema financiero, además, dependía del juicio de las agencias clasificadoras de riesgo (las cuales recibían compensación por su trabajo por parte de las empresas que solicitaban la clasificación de crédito, creando el incentivo de otorgar mejores clasificaciones para atraer clientes).

${ }^{9}$ Un movimiento de tres desviaciones estándares debiera ocurrir aproximadamente una vez cada tres años. Un movimiento de seis desviaciones estándares debiera ocurrir, en promedio, una vez cada cuatro millones de años. Un movimiento de siete desviaciones estándares no debiera verse más de una vez en toda la vida conocida del universo hasta la fecha, en promedio. Saltos de 25 desviaciones estándares son tan improbables que la probabilidad no se puede expresar en una escala cosmológica; los números no hacen sentido para nuestro universo. 


\section{Descuido: Fallas de la regulación y supervisión financiera}

En las secciones anteriores hemos discutido que si bien los particulares de la Gran Crisis son nuevos, ésta siguió un patrón antiguo y conocido. Muchas de sus causas - entre ellas miopía de desastres, riesgo moral, un ambiente de crédito fácil, una burbuja inmobiliaria y problemas de agencia - también deberían ser familiares para cualquier erudito en historia financiera. En esta sección analizamos cómo la crisis ocurrió a pesar de haber seguido este ritmo conocido, ya que había una infraestructura de regulación y supervisión dedicada a prevenir este tipo de eventos.

\section{VI.1. Fallas de supervisión}

Si bien la regulación financiera tenía una serie de problemas, que discutiremos en las subsecciones posteriores, en muchos casos otorgaba suficiente autoridad a las agencias supervisoras para examinar e intervenir a instituciones financieras que estuviesen actuando de una manera peligrosa.

El ejemplo más emblemático es el de la Securities and Exchange Commission de EE.UU. (SEC), la cual tenía autoridad para investigar a los bancos de inversión - dos de los cuales colapsaron durante la crisis. Bajo el Consolidated Supervised Entity Program, la agencia supervisora tenía, por lo menos en teoría, acceso a toda la información privada de la cual no disponía el mercado, incluyendo todas las inversiones que no se registraban en los estados financieros. Una auditoría de este programa durante la crisis ${ }^{10}$ indica, incluso, que la división de la SEC de transacciones y mercados a cargo de esta supervisión encontró un número de red flags, o señales de alerta, en Bear Stearns: concentración de riesgo hipotecario, alto nivel de apalancamiento, problemas en la gestión de riesgo financiero en instrumentos respaldados por hipotecas, y violaciones del espíritu de las reglas de Basilea II (un acuerdo internacional que norma el uso y límite de capital para bancos). La SEC no tomó acción alguna a pesar de tener conciencia de estos problemas.

1030 U.S. Securities and Exchange Commission, Office of Inspector General. 2008. SEC's Oversight of Bear Stearns and Related Entities: The Consolidated Supervised Entity Program. Report No. 446-A. September 24. 
Otra auditoría contemporánea ${ }^{11}$ de la supervisión de la SEC sobre todos los bancos de inversión concluye que la agencia falló en su labor supervisora, a tal nivel que no había normado cómo y cuándo debía entregársele la información, y que de los 146 broker-dealers (instituciones financieras que compran y venden activos en beneficio de otros, pero además hacen negocios propios) más importantes la SEC sólo investigaba en profundidad a seis. Los 140 restantes no recibían atención. Incluso con los seis broker-dealers a los que la SEC sí prestaba atención había atrasos en procesar y revisar la información financiera - y como vimos en el caso de Bear Stearns, no actuó a pesar de encontrar severas deficiencias en sus procesos operativos y manejo de riesgo.

Finalmente, cualquier evaluación del desempeño de la SEC estaría incompleta si no se menciona el caso del juego Ponzi de \$US 50.000 millones que llevó a cabo Bernard Madoff. La investigación oficial ${ }^{12}$ de este último tema asevera que el personal de la SEC no sabía del problema, y que tampoco hubo un esfuerzo por evitar investigarlo - es decir, no hubo corrupción de ningún tipo. Sin embargo, también reconoce que la SEC recibió más que suficiente información, detallada y sustentada, para justificar una investigación profunda del negocio de Madoff. Y reconoce que, a pesar de que se efectuaron tres exámenes y dos investigaciones, la competencia y profundidad de estos procedimientos fue completamente insuficiente. Lo sorprendente es que, tal como esta auditoría indica, no sólo presentaba el negocio de Madoff un total de seis red flags que indicaban que había algo extraño, probablemente deshonesto, que estaba ocurriendo en su negocio - además, profesionales financieros que habían llegado a esta conclusión escribieron cartas detalladas indicando los problemas y la posibilidad de fraude, y la SEC en su mayor parte las ignoró.

La incompetencia aquí demostrada es asombrosa, pero la SEC no fue la única agencia supervisora que falló en su labor. El FED y la Federal Deposit Insurance Corporation (FDIC) eran los supervisores de Citigroup, otra gran institución financiera que mantuvo un alto nivel de

1131 U.S. Securities and Exchange Commission, Office of Inspector General. 2008. SEC's Oversight of Bear Stearns and Related Entities: BrokerDealer Risk Assessment Program. Report No. 446-B. September 24.

1232 U.S. Securities and Exchange Commission, Office of Inspector General. 2009. Investigation of Failure of the SEC to Uncover Bernard Madoff's Ponzi Scheme. Report No. OIG-509. August 31. 
instrumentos riesgosos y necesitó una cantidad masiva de apoyo estatal durante la crisis para evitar la quiebra. El Financial Services Authority (FSA) del Reino Unido es un ente especializado que tenía la labor de supervisar el sistema bancario, y no intervino a Northern Rock -otra víctima temprana de la crisis financiera - a pesar que este banco hipotecario tenía una estrategia de financiamiento precaria, tenía la meta explícita de expandirse a un ritmo anual de $25 \%$ o más al año y tenía un nivel de endeudamiento vertiginoso: sus activos totales eran casi 60 veces su patrimonio accionario en junio del 2007. No sólo falló el FSA en censurar e intervenir al banco por estos motivos: le entregó licencia para aumentar su dividendo en $30 \%$ el 29 de junio de 2007, anticipando que iba a tener un "exceso de capital regulatorio" (con un apalancamiento financiero de casi 60 a 1) en los siguientes tres a cuatro años. $\mathrm{Ni}$ estuvo la incompetencia del FSA limitada a Northern Rock: tampoco censuró a Lloyds TSB, Royal Bank of Scotland o Barclays, todos los cuales hubieran quebrado durante la crisis a causa de su apalancamiento excesivo, y requirieron apoyo estatal para sobrevivir.

La calidad y alcance de la regulación financiera es irrelevante si no va acompañada de una supervisión adecuada. Muchas de las instituciones financieras que colapsaron durante la crisis se podrían haber diagnosticado como peligrosas e intervenido bajo el análisis y marco regulatorio existente. No es coincidencia que Canadá, que compartía muchas de las características de la regulación financiera de EE.UU., no haya tenido problemas de un calibre similar. Tampoco es coincidencia que España, que sufrió una severa burbuja inmobiliaria al mismo tiempo, haya tenido muchas menos dificultades y sus bancos hayan resistido la crisis en buen estado. Los problemas del sistema financiero español han estado centrados en las "Cajas" que tenían problemas serios de gobierno corporativo de larga data y que por su estructura de propiedad se hacía difícil su supervisión. Las cajas sufrieron además problemas con la concentración excesiva de su cartera en créditos inmobiliarios e hipotecarios, los sectores más afectados por la crisis. Las fallas de supervisión que hubo en los países más afectados fueron escandalosas y responsables en gran medida de permitir que la combinación de la expansión de crédito y fallas de mercado resultaran en la Gran Crisis Financiera.

¿A qué se deben las fallas en supervisión que hemos identificado? Los problemas más sustanciales que han encontrado distintas 
auditorías a las agencias supervisoras, sobre todo en EE.UU., son presupuesto y capacitación. En la práctica, la industria financiera y las agencias supervisoras son adversarios: la industria financiera percibe la regulación financiera como un obstáculo a la eficiencia y rentabilidad de su negocio, y es la labor del supervisor determinar si la regulación se aplica o no (y cuán bien).

La contienda es desigual: la industria financiera dispone de inmensos recursos y personal bien capacitado y muy bien remunerado. Las agencias supervisoras, por su parte, tienen una labor poco glamorosa y sus beneficios son más imperceptibles mientras mejor hacen su trabajo (¿cómo medir aquellas crisis y fraudes que no ocurren?), por lo que les es difícil aumentar su presupuesto y atraer talento. Más aún, ya que las oportunidades de carrera en supervisión financiera son limitadas, es común que profesionales financieros trabajen en una agencia supervisora para luego seguir su carrera en el sistema financiero, donde pueden traspasar todo su insider knowledge (conocimiento de los procedimientos internos de la agencia supervisora) para determinar en qué áreas la supervisión es más débil. Finalmente cabe notar que el sistema financiero tiene influencia política y es capaz de afectar indirectamente a aquellos que lo supervisan.

Así, las agencias supervisoras pasan de tener un presupuesto adecuado inmediatamente después de una crisis (cuando se percibe el valor de que éstas hagan su labor) a lentamente quedarse sin el presupuesto y personal necesarios para supervisar a una industria financiera en crecimiento. Evitar esto requeriría definir un presupuesto que se incrementara automáticamente a medida que crece el sistema financiero, establecer carreras profesionales en regulación y supervisión con compensación adecuada, y otorgarles un cierto grado de autonomía, como la que disfruta un banco central autónomo.

\section{VI.2. Requerimientos insuficientes de capital y liquidez}

Los requerimientos patrimoniales a los bancos, puestos en pie para disminuir su incentivo a tomar niveles imprudentes de riesgo, tenían tres problemas fundamentales:

- $\quad$ El nivel y calidad de capital exigido a los bancos se fijó demasiado bajo, tal que no fue capaz de absorber pérdidas excepcionales. 
- La estructura de requerimientos de capital y la valoración de activos agravaron la dinámica del ciclo de crédito (efecto procíclico).

- No contemplaba requerimientos mínimos de liquidez en el financiamiento.

El hecho que los requerimientos hayan sido insuficientes no debiera ser sorprendente: éstos no fueron diseñados para establecer un nivel óptimo de capital, sino simplemente para establecer una metodología de cálculo y un nivel mínimo común a nivel internacional. Los niveles de los requerimientos simplemente se negociaron de tal manera que fueran similares a la carga promedio que los bancos tenían en ese momento.

Esto no fue ideal, pero hacer compromisos internacionales no es fácil, y en su momento se consideró (y en realidad fue) un avance importante. El problema es que el esquema de Basilea tampoco parece haber tomado en cuenta los esfuerzos de los bancos por evitar la regulación que los encadenaba. Presumiblemente, el nivel de capital promedio que los bancos mantenían antes de que se estableciera el primer acuerdo, Basilea I, era el mínimo que éstos podían mantener bajo la regulación nacional del momento. El acuerdo de Basilea I estuvo diseñado para mantener este nivel de capital, pero tenía debilidades. Al explotar estas debilidades, los bancos pudieron cumplir con Basilea I y disminuir la cantidad efectiva de capital que mantenían. Cuando se promulgó Basilea II, que a su vez fue calibrado para igualar los requerimientos vigentes bajo Basilea I, el capital efectivo terminó disminuyendo aún más. Las figuras para JP Morgan Chase y Citigroup indican que la relación entre el capital regulatorio (tier 1 capital ratio) con una medida "dura" de capital tradicional (patrimonio accionario sobre activos tangibles) es tenue en el mejor de los casos: el primero se mantiene estable y crece a través del tiempo, mientras que el segundo ha caído sistemáticamente durante los últimos 15 años.

Con respecto al segundo punto, el problema radica en que los requerimientos de capital que se exigen a los bancos dependen del rating de crédito que tienen sus activos y de la medida de Value-at-Risk (VaR) que los bancos muestran para el período reciente. Ambos indicadores mejoran durante un ciclo expansivo de crédito y empeoran durante una contracción crediticia. En la práctica, esto implica que los bancos obtie- 
nen más libertad para prestar de manera desenfrenada durante tiempos de optimismo y se les exige ser más conservadores durante pánicos y contracciones crediticias. El problema es agravado por la manera particular en que la migración de clasificaciones afecta los requerimientos de capital.

Otra manera en que se manifiesta este problema es en el uso de contabilidad de mercado (mark-to-market). Ésta fuerza a instituciones financieras a reconocer pérdidas si el precio de mercado de sus activos cae, independientemente de si esta caída de precio refleja los fundamentos económicos del instrumento financiero o simplemente un pánico en que todos los compradores han desaparecido del mercado. Así, un pánico accionario sin justificación alguna puede causarle un daño patrimonial severo a una institución financiera, forzando una contracción de crédito (y potencialmente una quiebra) innecesaria.

Finalmente, la falta de requerimientos de liquidez incentiva a las instituciones financieras a mantener un perfil de financiamiento de corto plazo y a no guardar reservas prudentes en tiempos de bonanza, tal que una fuerte contracción del crédito y un ambiente de rechazo al riesgo pueden destruirla aun si es solvente. Ya que muchas instituciones financieras demostraron no tener reservas de capital suficientes y sufrieron problemas agudos de liquidez durante la crisis, las fallas regulatorias en estos aspectos ciertamente fueron relevantes.

\section{VI.3. Arbitraje regulatorio}

La regulación financiera tiene un rol antagónico con respecto a los administradores de la industria. Si ellos actuaran de manera prudente y responsable, la regulación sería innecesaria. Desafortunadamente, como hemos explorado en las secciones anteriores, tanto los dueños como los ejecutivos y los empleados del sistema financiero tienen algunos incentivos para actuar de manera imprudente, y por ende existe el anhelo de evadir la regulación como sea posible. En la práctica, las instituciones financieras ajustan todo, desde su estructura corporativa hasta sus modelos de negocios y los instrumentos que transan, para minimizar el efecto de la regulación sobre sus operaciones.

Este principio se manifestó durante la crisis de distintas maneras, algunas de las cuales hemos mencionado brevemente en secciones anteriores. Una de las manifestaciones más emblemáticas fue el uso de 
instituciones financieras que eran propiedad de la casa matriz del banco, pero que no aparecían en los estados financieros de éste (off-balance sheet vehicles) para evitar el escrutinio público de algunas de sus inversiones y escapar de los requerimientos de capital asociados a esas inversiones.

Otra manifestación fue la creación de un sistema bancario paralelo - conocido coloquialmente como el shadow banking system - que cumplía el mismo rol de intermediación que el sistema bancario tradicional en agregado, pero al usar estructuras legales distintas y separar cada uno de los roles del banco en varias instituciones, lograron escapar del esquema regulatorio bancario. El resultado final fue la creación de un sistema paralelo más complejo, más frágil, y cuya única ventaja competitiva fue la ausencia de regulación y supervisión financiera.

Una manifestación final fue la manera en que muchas de las instituciones financieras que colapsaron durante la crisis tuvieron la posibilidad de escoger qué agencia gubernamental sería su supervisor. AIG, Countrywide, IndyMac y Washington Mutual escogieron todos el Office of Thrift Supervision (OTS), la agencia más débil. La fragmentación de autoridad, en este sentido, lleva a que el sistema sea tan fuerte como su nexo más débil.

Como señalamos anteriormente, el arbitraje regulatorio llevó a que los peores abusos se cometieran en instituciones y mercados sin supervisión, como lo fue el mercado de instrumentos estructurados en que se empaquetaron muchas de las hipotecas más riesgosas, contribuyendo a un aumento en la complejidad del sistema financiero que no tuvo ninguna utilidad social.

\section{VI.4. Otras fallas regulatorias}

Si bien las tres fallas anteriores son las más importantes a nuestro juicio, tampoco fueron las únicas. Otra falla de menor alcance fue la ceguera, por parte de la infraestructura de supervisión financiera, al riesgo sistémico. Toda la atención de las agencias supervisoras estaba puesta en que cada institución, por sí sola, tuviera un comportamiento aceptable y se encontrase en buen estado. Si bien esto es importante, y su supervisión necesaria, evidentemente no es un método eficaz para diagnosticar, por ejemplo, una burbuja financiera. La concentración de riesgo hipotecario en grandes instituciones financieras americanas pue- 
de haber sido tolerable (aunque en el caso de Bear Stearns, como indica la auditoría del SEC que mencionamos anteriormente, era excesiva y debiera haber causado preocupación, tal como la exposición de Lehman Brothers a propiedades comerciales era imprudente), pero en conjunto representa un peligro latente. La falta de una buena perspectiva de qué estaba ocurriendo en los mercados financieros americanos en conjunto impidió reconocer el problema a tiempo, y una vez que éste había explotado, impidió diagnosticar y predecir qué instituciones tendrían problemas.

Otra falla de segundo orden fue la inconsistencia con que actuaron los reguladores durante la crisis. Como señalamos durante la crónica de la Gran Crisis Financiera en la sección II, la incertidumbre de quién sería salvado, quién no, y bajo qué condiciones se darían ambos casos, intensificó los nervios y la fuerte contracción de crédito en la segunda etapa. De la misma manera los procedimientos de rescate que se dieron antes de la quiebra de Lehman Brothers parecieron injustos y arbitrarios en el ámbito político, y crearon un ambiente en que rescatar a Lehman también hubiera sido inaceptable. De esta manera, haber establecido de antemano procedimientos y reglas para actuar en casos de crisis habría llevado a que la crisis reciente hubiese causado menos daños.

\section{Conclusiones}

Las crisis de los sistemas financieros se diferencian en mucho de las crisis que afectan a los sectores reales de una economía. Comenzamos este ensayo identificando un decálogo de características idiosincráticas de las crisis financieras, que tienden a observarse en la gran mayoría de ellas.

La Gran Crisis Financiera (GCF) de 2007-2009 no fue una excepción del patrón general que siguen las crisis financieras, aunque obviamente se manifestó en circunstancias y eventos idiosincráticos a ella. Sus causas combinan las condiciones macroeconómicas favorables al desarrollo de la bonanza — políticas monetarias y fiscales procíclicas, y un exceso de ahorro a nivel mundial que llevó a tasas de interés reales muy bajas - con fallas profundas en el funcionamiento de los mercados financieros, así como en la regulación y supervisión de dichos mercados por las autoridades de gobierno. El caso paradigmático donde se conjugaron con mayor intensidad la prociclicidad de las políticas 
macroeconómicas, la alta demanda internacional por activos financieros, las fallas de mercado y los errores en la regulación y supervisión financiera es EE.UU., país donde la crisis subprime se gestó y de donde se exportó a otros países industriales. No obstante, las fallas de políticas macroeconómicas y financieras no fueron monopolio de EE.UU.; muchos países europeos también cayeron en crisis financiera en 2008-2009 (y luego algunos de ellos cayeron en crisis fiscal en 2010-2011) por adoptar políticas macroeconómicas insostenibles y por carecer de una regulación y supervisión financiera adecuadas. El deterioro de la crisis de deuda soberana de Europa, que hoy incluso amenaza la existencia misma del euro, tiene mucho que ver con el mal manejo de la crisis de Grecia, Irlanda y Portugal, la incapacidad del gobierno de Italia de entender el cambio de situación y acometer acciones decididas para fortalecer la solvencia y crear condiciones para retomar el crecimiento, y la falta de decisión de las autoridades europeas de contrarrestar la pérdida de confianza de los mercados con un apoyo más sustancial a los países que tienen una alta probabilidad de mantenerse solventes, esto es, Italia y España. El deterioro del sector bancario europeo ha sido una consecuencia del deterioro de la crisis de solvencia de la deuda soberana, por sus efectos en la cartera de inversiones de los bancos que tienen bonos de los gobiernos afectados y por el deterioro de sus colaterales al momento de acceder a financiamiento. De otra parte, los bancos también sufren los efectos del deterioro del seguro implícito de rescate por parte de los gobiernos dado el deterioro de la solvencia de los soberanos.

Por lo tanto, la conjunción de fallas de política y de mercado generó una bonanza de crédito y de burbujas de precios de activos (especialmente inmobiliarios) que, apoyados por la innovación financiera y la integración financiera, se transmitieron rápidamente a través de los centros financieros del mundo desarrollado.

Como en todo auge insostenible de crédito y de precios de activos, las luces de alerta se prendieron con las quiebras de los primeros fondos inversores en las clases de activos más riesgosos; en este caso, los activos estructurados basados en créditos hipotecarios subprime de EE.UU. Con ello se inauguró una primera fase de turbulencias financieras, que luego dio lugar a la segunda fase de pánico financiero generalizado, gatillado por la quiebra de Lehman Brothers en septiembre de 2008. Para prevenir una implosión completa de los mercados financieros mundiales, los gobiernos y los bancos centrales de los países indus- 
triales adoptaron intervenciones financieras y políticas macroeconómicas expansivas que constituyen las más extensivas, intensivas, rápidas y coordinadas de la historia mundial. Con dichas medidas, muchas de ellas heterodoxas y sin precedentes históricos, se evitó el colapso financiero y una depresión económica de la magnitud de la Gran Depresión de los años 1930. Sin embargo, no se pudo evitar una recesión intensa en los países industriales, sólo aliviada por la continuación del crecimiento en los países en desarrollo.

La masiva intervención gubernamental adoptada entre septiembre de 1998 y enero de 2009 paró el congelamiento de los mercados financieros y permitió una rápida recuperación de los mismos, que marca la tercera fase a partir de marzo de 2009. La producción y el empleo en los países industriales comenzó una lenta recuperación a partir de mediados de 2009.

Podemos dividir las causas fundamentales de la crisis financiera en tres elementos: la oportunidad, generada por las condiciones macroeconómicas favorables al sobreendeudamiento, el gasto agregado excesivo y el desarrollo de burbujas de precios de activos. Luego, la voluntad por parte del público y el sistema financiero de aprovechar estas condiciones para crear una expansión económica y crediticia insostenible, que eventualmente debe derivar en una crisis. Finalmente, el descuido por parte de las autoridades cuya responsabilidad es regular y supervisar el sistema financiero, que permite que las distorsiones se acumulen.

En términos de oportunidades macroeconómicas, señalamos cuatro factores que en conjunto crearon un ambiente favorable para el desarrollo de la crisis. En primer lugar, un fuerte incremento en el nivel de ahorro por parte del mundo emergente, que creó una alta demanda por activos financieros seguros, llevando así a una caída en las tasas de interés real a nivel mundial y a una alta disponibilidad de crédito en países industriales. En segundo lugar, una estabilidad macroeconómica histórica que generó una confianza y un clima de optimismo sin precedentes. En tercer lugar, una política monetaria demasiado expansiva en EE.UU. y la Unión Europea, que facilitó el endeudamiento de corto plazo por parte del sistema financiero e incentivó así un aumento en la fragilidad del sistema. Y, en cuarto lugar, políticas fiscales procíclicas en muchos países industriales - especialmente en EE.UU. y el Reino Unido- que, lejos de ayudar a contener el ciclo de expansión económica, lo intensi- 
ficaron y contribuyeron a la creación de una burbuja en los precios de activos, tanto financieros como inmobiliarios. La combinación de todos estos factores creó el ambiente perfecto para una burbuja financiera.

El segundo elemento - la voluntad de aprovechar estas condiciones - responde a cuatro factores principales y otros menores. Primero, la miopía de desastres: una falla cognitiva que lleva al ser humano a sistemáticamente subestimar (en algunos casos, a ignorar completamente) la probabilidad de eventos desastrosos poco frecuentes. Éste es un componente tradicional de crisis financieras, que lleva a las personas a tomar decisiones y riesgos que en retrospectiva parecen imprudentes. Segundo, problemas de agencia: el quiebre del esquema en que una administración designada trabaja para el beneficio de quien lo contrata. Esto se dio en varios niveles en el sistema financiero: los traders actuaban en contra de los intereses de la administración ejecutiva, tomando riesgos excesivos que ocultaban, y la administración ejecutiva a su vez en contra de los intereses de los dueños de la institución, haciendo algo similar. El tercer factor es el fuerte aumento del nivel de complejidad del sistema financiero: mientras más complejo es un sistema, más difícil es de comprender. En un sistema no lineal, como lo es nuestra realidad, el costo de predecir la evolución del sistema aumenta de manera exponencial por cada incremento de complejidad. En la práctica, esto significó que muchos inversionistas no tenían plena conciencia de los riesgos de algunos de los instrumentos que compraban (en muchos casos éstos estaban opacados dada la complejidad del instrumento o transacción), la administración no tenía plena conciencia de los riesgos que su personal tomaba, los accionistas no tenían conocimiento de los riesgos que la administración tomaba, y tanto el sistema financiero como las autoridades sistemáticamente subestimaron la probabilidad y las consecuencias de una eventual crisis. Finalmente, el cuarto factor principal es el riesgo moral, que se refiere al incentivo perverso que tienen las instituciones financieras al anticipar la recepción de apoyo estatal en caso de problemas, lo que las lleva a tomar excesivo riesgo. Ellas perciben un escenario asimétrico: si un negocio riesgoso va bien, reciben un beneficio personal. Si el negocio riesgoso va mal, las pérdidas se socializan.

Dada la oportunidad y la voluntad para que se diese una crisis, queda el descuido por parte de las autoridades. La crisis financiera dejó al descubierto serias fallas en el sistema de supervisión financiera: aquellos organismos con la responsabilidad de velar porque se cum- 
plieran las reglas carecían del personal, los recursos y la mentalidad para cumplir su trabajo. El caso más emblemático es la Securities and Exchange Commission de EE.UU., que falló en su supervisión de los bancos de inversión y en detectar el fraude a escala masiva efectuado por Madoff a pesar de una serie de advertencias. Por el contrario, se distinguen las autoridades supervisoras de Canadá y España, que contaban con la misma regulación financiera pero la implementaron de manera ejemplar. Otro factor que contribuyó a este descuido fueron fallas en la regulación misma: los estándares que se exigían al sistema bancario y a los bancos de inversión eran demasiado permisivos, tal que la crisis de liquidez y las pérdidas generadas por la burbuja inmobiliaria causaron un daño suficiente para destruir al sistema financiero. Finalmente, el arbitraje regulatorio - el aprovechamiento de regímenes alternativos más débiles- llevó a la creación de un sistema bancario paralelo, conocido como el shadow banking system, que replicaba muchas de las actividades del sistema bancario tradicional, pero sin estar sujeto a la regulación y supervisión de éste - $-\mathrm{y}$, naturalmente, era sustancialmente más riesgoso.

Los gobiernos, los académicos y el sector privado han sido relativamente rápidos en diagnosticar las principales fallas de mercado y de política que llevaron a la GCF. Sin embargo, por diversos motivos (incluyendo la falta de consenso y la oposición de los sectores afectados) ha sido muy lenta la adopción de reformas para corregir las fallas más significativas.

Respecto de la responsabilidad de políticas macroeconómicas procíclicas, hay un fuerte consenso post crisis a favor de la adopción de instituciones y reglas fiscales que promuevan una política más neutral o contracíclica. En cuanto a la política monetaria, este consenso es más débil.

Sin embargo, existe un amplio apoyo internacional a la adopción de políticas macroprudenciales contracíclicas (provisiones y reservas procíclicas) y requerimientos mayores de capital para los bancos. Aunque existen propuestas explícitas de reformas sobre los temas anteriores al amparo del Financial Stability Board (FSB 2011), su adopción por los países aún se ve lejana.

Si bien podemos aprender lecciones importantes tanto de las crisis anteriores como de la actual, hay problemas que siempre estarán con nosotros: la miopía de desastres es inherente al ser humano y los proble- 
mas de agencia y el riesgo moral son intrínsecos a nuestras estructuras de gobierno corporativo y nuestros sistemas financieros. Es aun imposible alterar al ser humano para eliminar fallas cognitivas, ni tampoco hay nada cercano a un consenso de si y cómo reformar la estructura de propiedad ni el ordenamiento del sistema financiero. Una de las lecciones más importantes que podemos extraer de crisis anteriores es que tanto nosotros como nuestros predecesores han fallado en prevenirlas $-\mathrm{y}$ nuestros herederos seguramente lo harán también. En consecuencia, no corresponde enfocar nuestro esfuerzo sólo en prevenir crisis financieras, sino también en cómo diseñar un sistema que sea más robusto a fallas.

Con respecto a aquellos problemas que podemos controlar o evitar mediante mejor regulación y supervisión financiera, resaltamos el causado por complejidad. La innovación financiera no es necesariamente beneficiosa: instrumentos complejos aumentan el costo de observar, comprender y predecir al sistema, y así generan mayores oportunidades para abusos y agravan la incertidumbre durante períodos de crisis. Dentro de lo posible, se debiera incentivar el uso de instrumentos financieros y estructuras corporativas simples y transparentes. Otra medida importante es aumentar los recursos de las agencias de supervisión financiera y ofrecer mejores perspectivas a quienes trabajan en ellas. Quedó claro durante la crisis que hay problemas serios de financiamiento y personal calificado: el sistema financiero ha crecido a tal nivel que la infraestructura existente para supervisarlo es insuficiente.

Afortunadamente, algunas de las propuestas existentes han hecho un trabajo importante para arreglar falencias en la regulación financiera. El Comité de Basilea ha propuesto nuevos estándares de capital y liquidez mínimos para el sistema bancario, por ejemplo, que debieran aumentar de manera dramática la fortaleza de los bancos frente a shocks importantes. Tanto EE.UU. como la Unión Europea, cuyas instituciones financieras sufrieron los mayores daños durante la crisis, han planteado nuevas estructuras de supervisión para el sistema financiero. En el caso de Chile, también hay avances basados en las lecciones que arroja la GCF, en particular sobre el uso de políticas fiscales contracíclicas y sobre la cuantificación y la gestión de los riesgos sistémicos. El Comité Corbo ha entregado propuestas para reforzar la institucionalidad y la regla fiscal, incluyendo el fortalecimiento del rol anticíclico de la política fiscal (Corbo et al., 2011). La Comisión Desormeaux ha entregado propuestas para fortalecer la institucionalidad y la forma de supervisión de los bancos y las instituciones financieras no bancarias (Desormeaux et al., 2011). 


\section{REFERENCIAS}

Acemoglu, Daron. "The crisis of 2008: structural lessons for and from economics". Policy Insight, 28, 2009. Centre for Economic Policy Research. (http://www.cepr.org/pubs/PolicyInsights/CEPR_Policy_ Insight_028.asp)

Akerlof, George A. y Robert J. Shiller. Animal Spirits. Princeton y Oxford: Princeton University Press, 2009.

Allen, Franklin, Ana Babus y Elena Carletti. "Financial Crises: Theory and Evidence". Annual Review of Financial Economics Vol. 1, pp. 97-116 (2009). (http://finance.wharton.upenn.edu/ allenf/download/Vita/ ARFE-Crises-08June09-final.pdf)

Bank of International Settlements (BIS). "BIS Annual Report 2008/9". En "Annual Reports", 79, 29 de junio del 2009, Bank of International Settlements, Basilea. (http://www.bis.org/publ/arpdf/ar2009e.htm) - BIS Annual Report 2009/10. Basilea, 2010.

Bean, Charles, Matthias Paustian, Adrian Penalver y Tim Taylor. "Monetary Policy after the Fall". Trabajo presentado en el Federal Reserve Bank of Kansas City Economic Symposium, Jackson Hole, Wyoming, 2010.

Bernanke, Ben. "Asset price 'bubbles' and monetary policy”. Comentarios en el New York Chapter of the National Association of Business Economics. New York, 15 de octubre del 2002. (http://www.federalreserve.gov/ BoardDocs/Speeches/2002/20021015/default.htm) "The Global Saving Glut and the U.S. Current Account Deficit". Presentado en el Sandridge Lecture, Virginia Association of Economics, 10 de marzo del 2005, en Richmond, Virginia, EE.UU. (http:/www.bis. org/review/r050318d.pdf)

"Financial Reform to Address Systemic Risk". Discurso en el Council on Foreign Relations, 10 de marzo de 2009, en Washington, D.C., EE.UU. (2009a) (http://www.federalreserve.gov/newsevents/ speech/bernanke20090310a.htm)

- "Lessons of the Financial Crisis for Banking Supervision". Discurso en el Federal Reserve Bank of Chicago Conference on Bank Structure and Competition, 7 de mayo del 2009, en Chicago, Illinois, EE.UU. (2009b) (http://www.federalreserve.gov/newsevents/speech/ bernanke20090507a.htm)

"Monetary Policy and the Housing Bubble". Discurso en el Congreso Anual del American Economic Association, Atlanta, GA, 2010 .

Blanchard, Olivier. "The Crisis: Basic Mechanisms and Appropriate Policies". Working Paper 09/80, abril del 2008. Fondo Monetario Internacional, Washington, D.C. (http://papers.ssrn.com/sol3/papers.cfm?abstract_ $\mathrm{id}=1394780$ )

Caballero, Ricardo. "Sudden Financial Arrest". IMF Economic Review, Vol. 58, No. 1, pp. 6-36 (2010). (http://papers.ssrn.com/sol3/papers. cfm?abstract_id=1693360) 
Caballero, R. y A. Krishnamurthy. "International and Domestic Collateral Constraints in a Model of Emerging Markets Crisis". Journal of Monetary Economics, Vol. 48, No. 3, pp. 513-548 (2001). (http://www. nber.org/papers/w7971)

"Collective Risk Management in a Flight to Quality Episode". Journal of Finance, Vol. 63, No. 5, 2008.

Caballero, Ricardo, Emmanuel Farhi y Pierre-Olivier Gourinchas. "Financial Crash, Commodity Prices and Global Imbalances." Brookings Papers on Economic Activity, 2008 (2), pp. 1-55. (http://www.nber.org/papers/ w14521.pdf)

Caballero, Ricardo y Alp Simsek. "Complexity and Financial Panics". NBER Working Paper No. 14997, 2009. (http://www.nber.org/papers/w14997)

Calomiris, Charles W. "The subprime turmoil: What's Old, What's New, and What's Next?" VOX, 22 de agosto del 2008. (http://voxeu.org/index. php?q=node/1561)

Calvo, G. "Explaining Sudden Stops, Growth Collapse and BOP Crises: The Case of Distortionary Output Taxes". IMF Mundell-Fleming Lecture, IMF Staff Papers, 2003.

Central Bank of Chile. 2008. Financial Stability Report First Half 2008. http:// www.bcentral.cl/eng/publications/policies/pdf/fer1_2008.pdf.

Chang, A. y A. Velasco. "A Model of Financial Crises in Emerging Markets". Quarterly Journal of Economics, 489-517, 2001.

Cherny, Kent y Yuliya Demyanyk. "Subprime mortgages: Myths and reality". VOX. 17 de octubre, 2009. (http://voxeu.org/index.php?q=node/4102)

Corbo, Vittorio, Ricardo Caballero, Mario Marcel et al. "Propuesta para Perfeccionar la Regla Fiscal: Informe Final del Comité Asesor para el Diseño de una Política Fiscal de Balance Estructural de Segunda Generación para Chile”. 2011.

Corbo, Vittorio y Klaus Schmidt-Hebbel. "The International Crisis and Latin America: Growth Effects and Development Strategies". En M. Haddad y B. Shepherd (editores), Managing Openess. Trade and OutwardOriented Growth after the Crisis. Washington, D.C.: The World Bank, 2011.

Curry, Timothy y Lynn Shibut. "The Cost of the Savings and Loan Crisis: Truth and Consequences". FDIC Banking Review, 13(2), 26-35 (2002).

Desormeaux, Jorge E., Arturo Cifuentes, Luis Cordero et al. "Informe Final de la Comisión de Reforma a la Regulación y Supervisión Financiera". 2011. (http://www.hacienda.cl/documento/descargar/id/4103)

Diamond, D. y P. Dybvig. "Bank Runs, Deposit Insurance, and Liquidity". Journal of Political Economy 91: 401-19, 1983.

Dooley, Michael P., David Folkerts-Landau y Peter M. Garber. "Bretton Woods II Still Defines the International Monetary System". Pacific Economic Review, 14(3), 297-311, 2009. (http://www.nber.org/papers/w14731)

Dowd, Kevin, John Cotter, Chris Humphrey y Margaret Woods. "How Unlucky is 25-Sigma?” Working Paper, 2008. (http://ssrn.com/abstract=1517146) 
Einhorn, David. "Private Profits and Socialized Risk". Discurso en Grant's Spring Investment Conference, 8 de abril del 2008. (http:// manualofideas.com/files/blog/einhornspeech200804.pdf)

Eisenhardt, Kathleen M. "Agency Theory: An Assessment and Review". The Academy of Management Review 14(1), 57-74, 1989. (http://www.jstor. org/stable/258191)

Federal Reserve. Report Pursuant to Section 129 of the Emergency Economic Stabilization Act of 2008: Bridge Loan to The Bear Stearns Companies Inc. through JP Morgan Chase Bank, N.A, 2008. (http://www. federalreserve.gov/monetarypolicy/files/129bearstearnsbridgeloan.pdf)

Feldstein, Martin. "Rethinking the Role of Fiscal Policy". American Economic Review 99(2): 556-559, 2009. (http://www.nber.org/papers/w14684)

Financial Stability Board. "Macroprudential Policy Tools and Frameworks", 2011. (http://www.financialstabilityboard.org/publications/r_1103.pdf)

Fondo Monetario Internacional. "Lessons of the Global Crisis for Macroeconomic Policy". Research Department, FMI. 19 de febrero de 2009 (2009a). (http://www.imf.org/external/np/pp/eng/2009/021909. pdf)

"Lessons of the Financial Crisis for Future Regulation of Financial Institutions and Markets and for Liquidity Management”. Monetary and Capital Markets Department, FMI. 4 de febrero de 2009 (2009b). (http://www.imf.org/external/np/pp/eng/2009/020409.pdf)

"Debt Bias and Other Distorsions: Crisis-Related Issues in Tax Policy". Fiscal Affairs Department, FMI. 12 de junio del 2009 (2009c). (http://www.imf.org/external/np/pp/eng/2009/061209.pdf)

"World Economic Outlook October 2009", octubre (2009d). Fondo Monetario Internacional, Washington D.C. (http://www.imf.org/ external/pubs/ft/weo/2009/02/index.htm)

Goldfajn, I. y R. Valdés: "Capital Flows and the Twin Crisis: The Role of Liquidity”. IMF Working Paper n. 97/98, 1997. (http://www.imf.org/ external/pubs/ft/wp/wp9787.pdf)

Goodhart, Charles y Miguel Segoviano. "Basel and Procyclicality: A Comparison of the Standardized and IRB Approaches to an Improved Credit Risk Method". London School of Economics, Financial Markets Group, Discussion Paper 524, 2004. (http://fmg.1se.ac.uk/upload file/426_DP524.pdf)

Greenspan, Alan. "Opening Remarks". Discurso en un seminario auspiciado por el Federal Reserve Bank of Kansas City, 30 de agosto de 2002, en Jackson Hole, Wyoming, U.S.A. (http://www.federalreserve.gov/ boarddocs/speeches/2002/20020830/)

"The Crisis." Brookings Papers on Economic Activity, primavera 2010. (http://www.brookings.edu/ /media/Files/Programs/ES/ BPEA/2010_spring_bpea_papers/spring2010_greenspan.pdf)

Guttentag, Jack y Richard J. Herring. "Credit Rationing and Financial Disorder”. Journal of Finance 39(5), 1359-1382, 1984. (http://www. jstor.org/stable/2327732) 
Haldane, Andrew. "Why Banks Failed the Stress Test". Discurso en el MarcusEvans Conference on Stress-Testing, 9 y10 de febrero de 2009. (http:// www.bankofengland.co.uk/publications/speeches/2009/speech374.pdf)

Herring, Richard J. "Credit risk and financial instability." Oxford Review of Economic Policy 15(3), 63-79, 1999. (http://oxrep.oxfordjournals.org/ cgi/content/abstract/15/3/63).

Kahneman, Daniel, Paul Slovic y Amos Tversky. Judgment under Uncertainty: Heuristics and Biases. Cambridge and New York: Cambridge University Press, 1982.

Kareken, John y Neil Wallace. "Deposit Insurance and Bank Regulation: A Partial Equilibrium Exposition". Journal of Business 51 (julio de 1978), 413-438. (http://www.minneapolisfed.org/publications_papers/ pub_display.cfm?id=297)

Kiff, John y Paul S. Mills. "Money for Nothing and Checks for Free: Recent Developments in U.S. Subprime Mortgage Markets". IMF Working Paper, WP/07/188, 2007. (http://papers.ssrn.com/sol3/papers. cfm?abstract id=1006316)

Kindleberger, Charles P. Manias, Panics and Crashes [1978], Wiley, $5^{\text {a edición, }}$ 2005.

Kohn, Donald L. "John Taylor Rules." Discurso en la conferencia John Taylor's Contributions to Monetary Theory and Policy, Federal Reserve Bank of Dallas. 12 de octubre de 2007 en Dallas, Texas. (http://www. federalreserve.gov/newsevents/speech/kohn20071012a.htm)

McDonald, Lawrence G. A Colossal Failure of Common Sense: The Inside Story of the Collapse of Lehman Brothers. Crown Business, 2009.

Minksy, Hyman. Stabilizing an Unstable Economy. Yale University Press, 1986.

Obstfeld, Maurice y Kenneth Rogoff. "Global Imbalances and the Financial Crisis: Products of Common Causes”. CEPR Discussion Papers 7606, 2009.

Orphanides, Athanasios. "Monetary policy evaluation with noisy information". Journal of Monetary Economics, abril de 2003, 50(3), 605-631. (http:// www.federalreserve.gov/pubs/feds/1998/199850/199850pap.pdf)

Orphanides, Athanasios y John C. Williams. "Monetary Policy with Imperfect Knowledge". Journal of the European Economic Association, 2006, 4(2-3), 366-375. (http://www.federalreserve.gov/pubs/ feds/2005/200551/200551pap.pdf)

Persaud, Avinash. "The Tobin Tax: Feasible, Desirable?" Entrevista por Romesh Vaitilingam. VOX. 30 de octubre de 2009.

Reinhart, Carmen M. y Kenneth Rogoff. This Time is Different: Eight Centuries of Financial Folly. Princeton University Press, 1ª edición, 2009.

Repullo, Rafael y Javier Suárez. "The Procyclical Effects of Basel II". Presentado en la 9th Jacques Polak Annual Research Conference, 13-14 de noviembre de 2008, en Washington, D.C. (http://ideas.repec.org/p/ cpr/ceprdp/6862.html) 
Rudebusch, Glenn D. "The Fed's Monetary Policy Response to the Current Crisis". FRBSF Economic Letter, 22 de mayo de 2009. (http://www. frbsf.org/publications/economics/letter/2009/el2009-17.html)

Sorkin, Andrew R. Too Big to Fail: The Inside Story of How Wall Street and Washington Fought to Save the Financial System - and Themselves. Viking Adult, 2009.

Svensson, Lars E. O. "Monetary Policy after the Financial Crisis". Discurso en el Second International Journal of Central Banking (IJCB), Fall Conference, Tokio, 17 de septiembre del 2010.

Taleb, Nassim N. The Black Swan: The Impact of the Highly Improbable. Random House, 2007.

Taylor, John B. "The Financial Crisis and the Policy Responses: An Empirical Analysis of What Went Wrong". Keynote Address at Bank of Canada. Noviembre de 2008. (http://www.bank-banque-canada.ca/en/ conference/2008/taylor.pdf)

- "Systemic Risk and the Role of Government." Discurso en el Conference on Financial Innovation and Crises, Federal Reserve Bank of Atlanta, 12 de mayo de 2009a, en Jekyll Island, Georgia, EE.UU. (http://www.frbatlanta.org/news/CONFEREN/09fmc/taylor.pdf)

"The Lack of an Empirical Rationale for a Revival of Discretionary Fiscal Policy". American Economic Review 99 (2): 550-555, 2009 b. (http://www.atypon-link.com/AEAP/doi/abs/10.1257/aer.99.2.550)

Turner Review. "A Regulatory Response to the Global Banking Crisis". London: Financial Services Authority, 2009. (http://www.fsa.gov.uk/ pubs/other/turner_review.pdf) 